\title{
System Characterization Report on Resourcesat-2 Linear Imaging Self Scanning-3 (LISS-3) Sensor
}

\section{Chapter $\mathrm{H}$ of}

System Characterization of Earth Observation Sensors

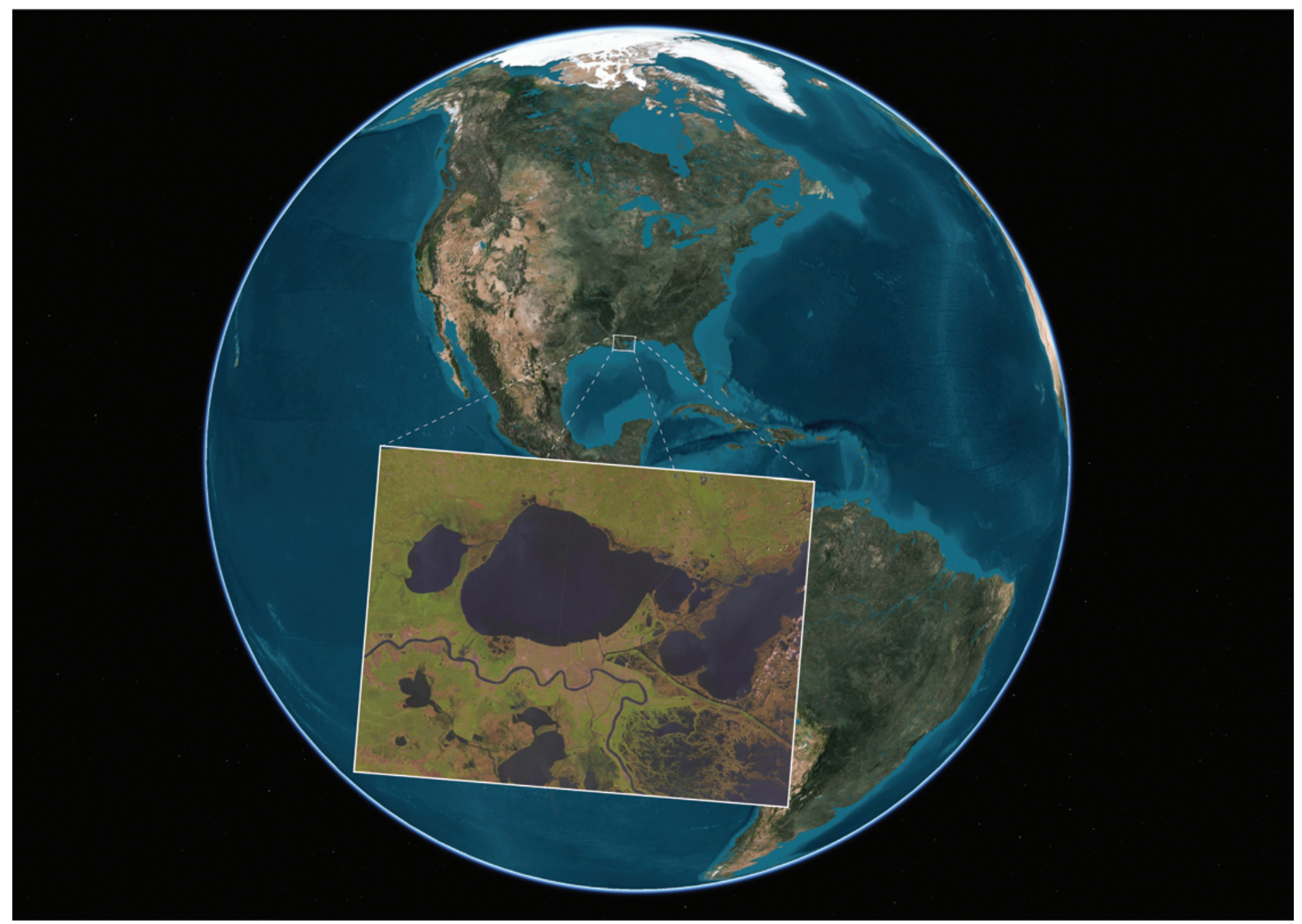

Open-File Report 2021-1030-H

U.S. Department of the Interior U.S. Geological Survey 
Cover: Image of Lake Pontchartrain and the coast of Louisiana captured by the Resourcesat-2 Linear Imaging Self Scanning-3 sensor. Image by the U.S. Geological Survey. Image of Earth from Analytical Graphics, Inc., Systems Tool Kit. 


\section{System Characterization Report on Resourcesat-2 Linear Imaging Self Scanning-3 (LISS-3) Sensor}

By Shankar N. Ramaseri Chandra, ${ }^{1}$ Jon Christopherson, ${ }^{1}$ Cody Anderson, ${ }^{2}$ Gregory L. Stensaas, ${ }^{2}$ and Minsu Kim ${ }^{1}$

Chapter $\mathrm{H}$ of

System Characterization of Earth Observation Sensors

Compiled by Shankar N. Ramaseri Chandra ${ }^{1}$

${ }^{1} \mathrm{KBR}$, Inc., under contract to the U.S. Geological Survey.

${ }^{2}$ U.S. Geological Survey.

Open-File Report 2021-1030-H 


\section{U.S. Geological Survey, Reston, Virginia: 2021}

For more information on the USGS - the Federal source for science about the Earth, its natural and living resources, natural hazards, and the environment—visit https://www.usgs.gov or call 1-888-ASK-USGS.

For an overview of USGS information products, including maps, imagery, and publications, visit https://store.usgs.gov/.

Any use of trade, firm, or product names is for descriptive purposes only and does not imply endorsement by the U.S. Government.

Although this information product, for the most part, is in the public domain, it also may contain copyrighted materials as noted in the text. Permission to reproduce copyrighted items must be secured from the copyright owner.

Suggested citation:

Ramaseri Chandra, S.N., Christopherson, J., Anderson, C., Stensaas, G.L., and Kim, M., 2021, System characterization report on Resourcesat-2 Linear Imaging Self Scanning-3 (LISS-3) sensor, chap. H of Ramaseri Chandra, S.N., comp., System characterization of Earth observation sensors: U.S. Geological Survey Open-File Report 2021-1030, 25 p., https://doi.org/10.3133/ofr20211030H.

ISSN 2331-1258 (online) 


\section{Contents}

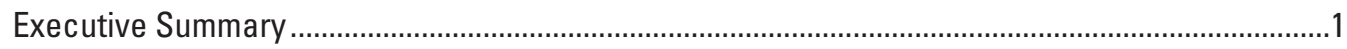

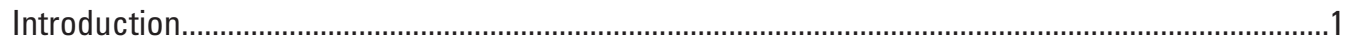

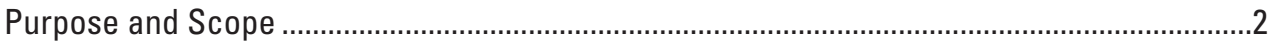

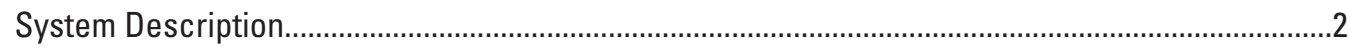

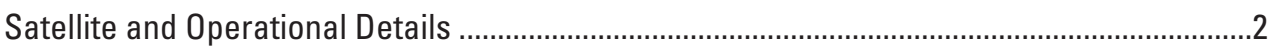

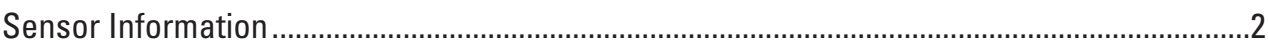

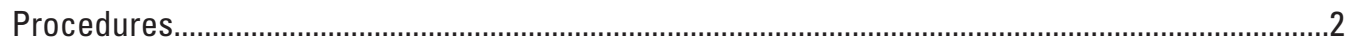

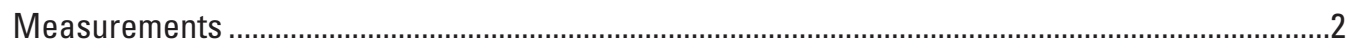

Analysis

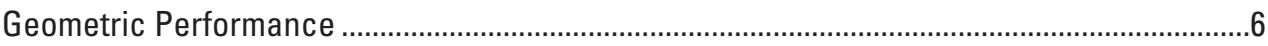

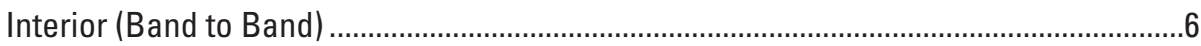

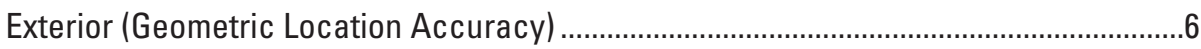

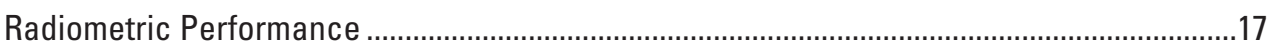

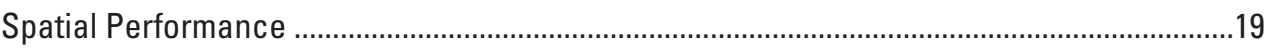

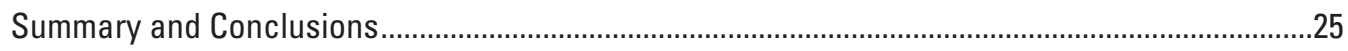

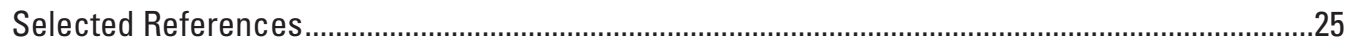

\section{Figures}

1. Graph showing Resourcesat-2 Linear Imaging Self Scanning-3 relative spectral

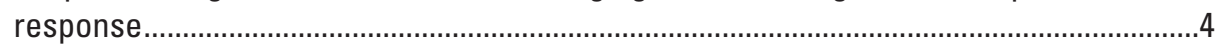

2. Band 2 to band 3 geometric error map for New Mexico ................................................

3. Band 2 to band 3 geometric error histogram and error distribution for New Mexico ......8

4. Band 3 to band 5 geometric error map for New Mexico ..................................................9

5. Band 3 to band 5 geometric error histogram and error distribution for New Mexico ....10

6. Map showing relative geometric error for Landsat 80 perational Land Imager and Resourcesat-2 Linear Imaging Self Scanning-3 for Fargo, North Dakota.................12

7. Relative geometric error histogram and error distribution for Fargo, North Dakota ......13

8. Map showing relative geometric error for Landsat 80 perational Land Imager and Resourcesat-2 Linear Imaging Self Scanning-3 for Maine......................................14

9. Relative geometric error histogram and error distribution for Maine ............................15

10. Map showing relative geometric error for Landsat 8 Operational Land Imager and Resourcesat-2 Linear Imaging Self Scanning-3 for New Mexico ..............................16

11. Relative geometric error histogram and error distribution for New Mexico....................17

12. Graphs showing Top of Atmosphere reflectance comparison for Landsat 8 Operational Land Imager and Resourcesat-2 Linear Imaging Self Scanning-3...............18

13. Resourcesat-2 Linear Imaging Self Scanning-3 image region of interest

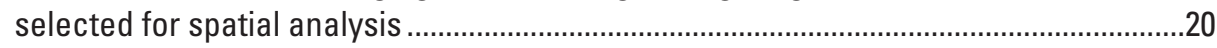

14. Graphs showing band 2 raw edge transects and aligned transects .............................21

15. Graphs showing band 2 edge spread function and line spread function and

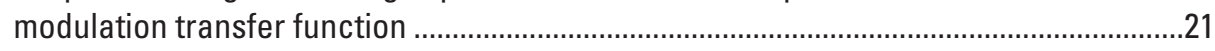

16. Graphs showing band 3 raw edge transects and aligned transects ............................22

17. Graphs showing band 3 edge spread function and line spread function and modulation transfer function 
18. Graphs showing band 4 raw edge transects and aligned transects ..............................23

19. Graphs showing band 4 edge spread function and line spread function and

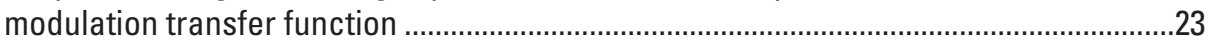

20. Graphs showing band 5 raw edge transects and aligned transects ..............................24

21. Graphs showing band 5 edge spread function and line spread function and modulation transfer function

\section{Tables}

1. Satellite and operational details for Resourcesat-2 Linear Imaging Self Scanning-3......3

2. Imaging sensor details for Resourcesat-2 Linear Imaging Self Scanning-3 .....................4

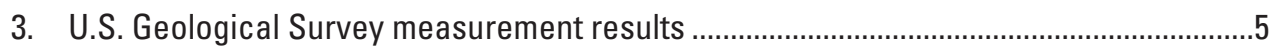

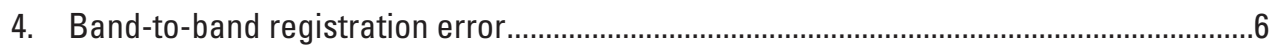

5. Geometric error of Resourcesat-2 Linear Imaging Self Scanning-3 relative to Landsat 8 Operational Land Imager..

6. Top of Atmosphere reflectance comparison of Resourcesat-2 Linear Imaging Self Scanning-3 against Landsat 8 Operational Land Imager.

7. Spatial performance of Resourcesat-2 Linear Imaging Self Scanning-3.

\section{Conversion Factors}

International System of Units to U.S. customary units

\begin{tabular}{llll}
\hline & Multiply & By & \multicolumn{1}{c}{ To obtain } \\
\hline & Length & \\
\hline meter $(\mathrm{m})$ & 3.281 & foot $(\mathrm{ft})$ \\
meter $(\mathrm{m})$ & 1.094 & yard $(\mathrm{yd})$ \\
\hline
\end{tabular}

\section{Abbreviations}

$\begin{array}{ll}\text { ECCOE } & \text { EROS CaI/Val Center of Excellence } \\ \text { EROS } & \text { Earth Resources Observation and Science } \\ \text { EROSSC } & \text { EROS System Characterization } \\ \text { GSD } & \text { ground sample distance } \\ \text { JACIE } & \text { Joint Agency Commercial Imagery Evaluation } \\ \text { LISS-3 } & \text { Linear Imaging Self Scanning-3 } \\ \text { OLI } & \text { Operational Land Imager } \\ \text { RMSE } & \text { root mean square error } \\ \text { STDDEV } & \text { standard deviation } \\ \text { USGS } & \text { U.S. Geological Survey }\end{array}$




\title{
System Characterization Report on Resourcesat-2 Linear Imaging Self Scanning-3 (LISS-3) Sensor
}

\author{
By Shankar N. Ramaseri Chandra, ${ }^{1}$ Jon Christopherson, ${ }^{1}$ Cody Anderson, ${ }^{2}$ Gregory L. Stensaas, ${ }^{2}$ and \\ Minsu Kim
}

\section{Executive Summary}

This report addresses system characterization of the Indian Space Research Organisation Resourcesat-2 Linear Imaging Self Scanning-3 (LISS-3) sensor and is part of a series of system characterization reports produced and delivered by the U.S. Geological Survey Earth Resources Observation and Science $\mathrm{Cal} / \mathrm{Val}$ Center of Excellence in 2021. These reports present and detail the methodology and procedures for characterization; present technical and operational information about the specific sensing system being evaluated; and provide a summary of test measurements, data retention practices, data analysis results, and conclusions.

Resourcesat-2 is a medium-resolution satellite launched in 2011 on the Polar Satellite Launch Vehicle-C16 launch vehicle. Resourcesat- 2 carries the same sensing elements as Resourcesat-1 (launched in October 2003) and provides continuity for the mission. The objectives of the Resourcesat mission are to provide remote sensing data services to global users, focusing on data for integrated land and water resources management.

Resourcesat-2A is identical to Resourcesat-2 and was launched in 2016 on the Polar Satellite Launch VehicleC36 launch vehicle for continuity of data and improved temporal resolution. The two satellites operating in tandem improved the revisit capability from 5 days to $2-3$ days. The Resourcesat-2 platform is of Indian Remote Sensing Satellites-1C/1D-P3 heritage and was built by the Indian Space Research Organisation. Resourcesat-2 and Resourcesat2A carry the Advanced Wide Field Sensor and LISS-3, as well as the Linear Imaging Self Scanning-4 for medium-resolution imaging. More information on Indian Space Research Organisation satellites and sensors is available in the "2020 Joint Agency Commercial Imagery Evaluation-Remote Sensing Satellite Compendium" and from the manufacturer at https://www.isro.gov.in/.

\footnotetext{
${ }^{1}$ KBR, Inc., under contract to the U.S. Geological Survey.
}

${ }^{2}$ U.S. Geological Survey.
The Earth Resources Observation and Science Cal/Val Center of Excellence system characterization team completed data analyses to characterize the geometric (interior and exterior), radiometric, and spatial performances. Results of these analyses indicate that LISS- 3 has an interior geometric performance in the range of -4.620 ( -0.154 pixel) to 13.230 meters (m; 0.441 pixel) in easting and $-12.360(-0.412$ pixel) to $1.500 \mathrm{~m}(0.050$ pixel) in northing in band-to-band registration, an exterior geometric error of -27.805 ( -0.927 pixel) to $26.578 \mathrm{~m}$ ( 0.886 pixel) in easting and -35.341 ( -1.178 pixel $)$ to $-6.286 \mathrm{~m}(-0.210$ pixel $)$ in northing offset in comparison to the Landsat 8 Operational Land Imager, a radiometric performance in the range of -0.108 to 0.104 in offset and $0.585-0.946$ in slope, and a spatial performance in the range of 2.52-2.57 pixels for full width at half maximum, with a modulation transfer function at a Nyquist frequency in the range of $0.018-0.028$.

\section{Introduction}

The Linear Imaging Self Scanning-3 (LISS-3) sensor onboard the Indian Space Research Organisation Resourcesat-2 satellite is a high-resolution land observation instrument consisting of four bands: green, red, near infrared, and shortwave infrared. Resourcesat-2 was launched in 2011, and an identical mission, Resourcesat-2A, was launched in 2016. The primary objectives for data acquired by LISS-3 include monitoring biomass, vegetation, land cover, leaf area index, and normalized difference vegetation index.

The data analysis results provided within this report have been derived from approved Joint Agency Commercial Imagery Evaluation (JACIE) processes and procedures. JACIE was formed to leverage resources from several Federal agencies for the characterization of remote sensing data and to share those results across the remote sensing community. More information about JACIE is available at https://www.usgs.gov/ core-science-systems/eros/calval/jacie?qt-science_support page_related_con=3\#qt-science_support_page_related_con. 


\section{Purpose and Scope}

The purpose of this report is to describe the specific sensor or sensing system, test its performance in three categories, complete related data analyses to quantify these performances, and report the results in a standardized document. In this chapter, the LISS-3 sensor is described. The performance of the system is limited to geometric, radiometric, and spatial analyses. The scope of the geometric assessment is limited to testing the interior alignments of spectral bands against each other and testing the exterior alignment in reference to the Landsat 8 Operational Land Imager (OLI).

The U.S. Geological Survey (USGS) Earth Resources Observation and Science (EROS) Cal/Val Center of Excellence (ECCOE) project, and the associated system characterization process used for this assessment, follows the USGS Fundamental Science Practices, which include maintaining data, information, and documentation needed to reproduce and validate the scientific analysis documented in this report. Additional information and guidance about Fundamental Science Practices and related resource information of interest to the public are available at https://www .usgs.gov/about/organization/science-support/office-sciencequality-and-integrity/fundamental-science-practices. For additional information related to the report, please contact ECCOE at eccoe@usgs.gov.

\section{System Description}

This section describes the satellite and operational details for Resourcesat- 2 and provides information about the LISS-3 sensor.

\section{Satellite and Operational Details}

The satellite and operational details of Resourcesat- 2 are listed in table 1 .

\section{Sensor Information}

The spectral characteristics and the relative spectral response are listed in table 2 and figure 1, respectively.

\section{Procedures}

ECCOE has established standard processes to identify Earth observing systems of interest and to assess the geometric, radiometric, and spatial qualities of data products from these systems.

The assessment steps are as follows:

- system identification and investigation to learn the general specifications of the satellite and its sensor(s);

- data receipt and initial inspection to understand the characteristics and any overt flaws in the data product so that it may be further analyzed;

- geometry characterization, including interior geometric orientation measuring the relative alignment of spectral bands and exterior geometric orientation measuring how well the georeferenced pixels within the image are aligned to a known reference;

- radiometry characterization, including assessing how well the data product correlates with a known reference and, when possible, assessing the signal-to-noise ratio; and

- spatial characterization, assessing the two-dimensional fidelity of the image pixels to their projected ground sample distance (GSD).

Data analysis and test results are maintained at the USGS EROS Center by the ECCOE project.

\section{Measurements}

The observed USGS measurements are listed in table 3. The mean of interior (band-to-band) and exterior (image-toimage) mean errors, standard deviation (STDDEV), and root mean square errors (RMSEs) are listed in meters (pixels). Details about the methodologies used are outlined in the "Analysis" section. 
Table 1. Satellite and operational details for Resourcesat-2 Linear Imaging Self Scanning-3.

[kg, kilogram; NIR, near infrared; SWIR, shortwave infrared; W, watt; AH, amp hour; Ni-Cd, nickel-cadmium; Mbps, megabit per second; , about; km, kilometer; ${ }^{\circ}$, degree; min, minute; \pm , plus or minus; lat., latitude; N/A, not applicable; m, meter; USGS, U.S. Geological Survey]

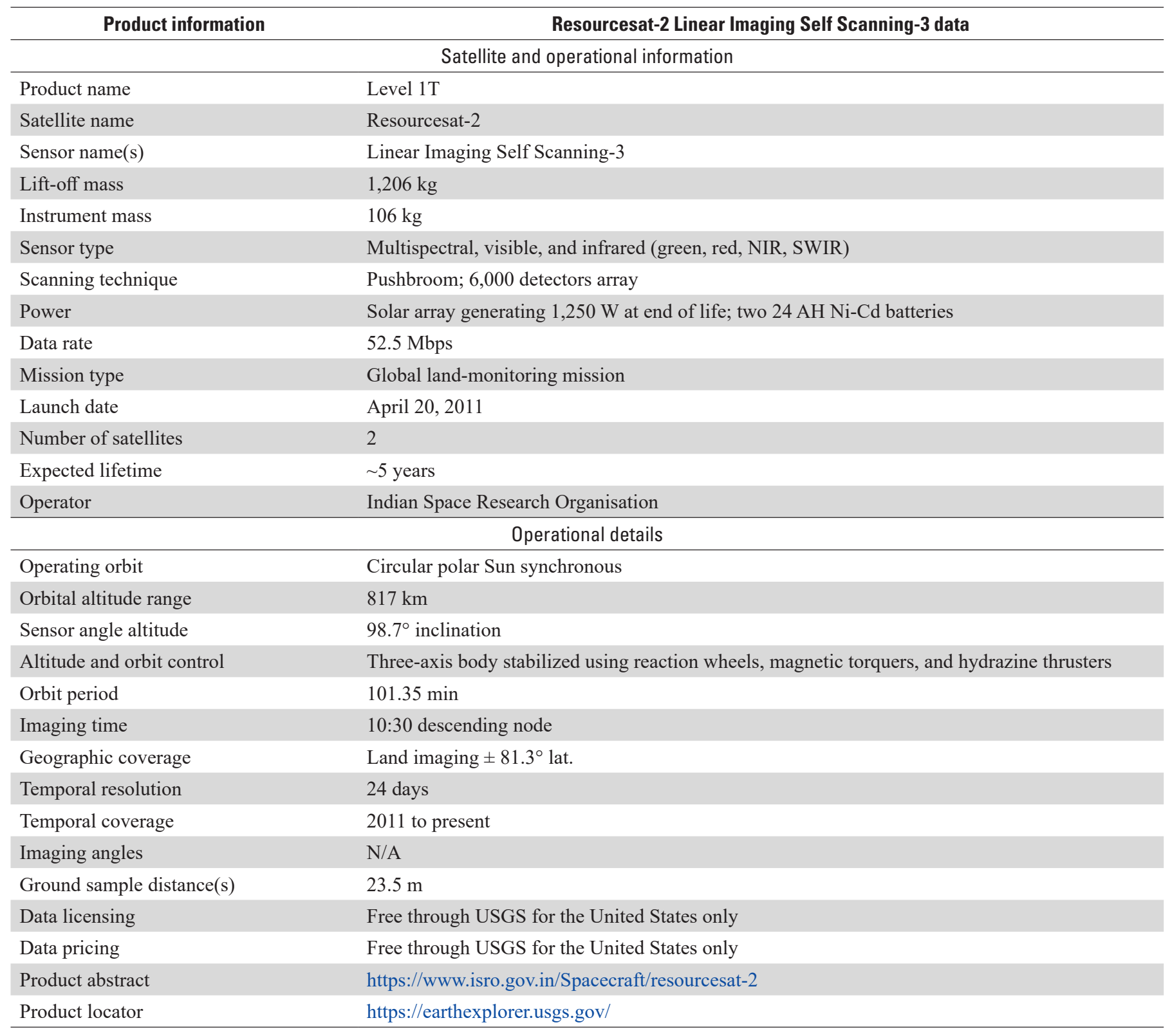


Table 2. Imaging sensor details for Resourcesat-2 Linear Imaging Self Scanning-3.

[The Resourcesat-2 Linear Imaging Self Scanning-3 (LISS-3) sensor has a swath width of 140 kilometers; $\mu$ m, micrometer; m, meter; NIR, near infrared; SWIR, shortwave infrared]

\begin{tabular}{lcccc}
\hline \multirow{2}{*}{ Spectral band(s) details } & \multicolumn{3}{c}{ Resourcesat-2 LISS-3 } \\
\cline { 2 - 5 } & $\begin{array}{c}\text { Lower band } \\
(\boldsymbol{\mu m})\end{array}$ & $\begin{array}{c}\text { Upper band } \\
(\boldsymbol{\mu m})\end{array}$ & $\begin{array}{c}\text { Radiometric resolution } \\
(\mathbf{b i t s})\end{array}$ & $\begin{array}{c}\text { Ground sample distance } \\
(\mathbf{m})\end{array}$ \\
\hline Band 2-green & 0.52 & 0.59 & 10 & 23.5 \\
Band 3-red & 0.62 & 0.68 & 10 & 23.5 \\
Band 4-NIR & 0.77 & 0.86 & 10 & 23.5 \\
Band 5-SWIR & 1.55 & 1.70 & 10 & 23.5 \\
\hline
\end{tabular}

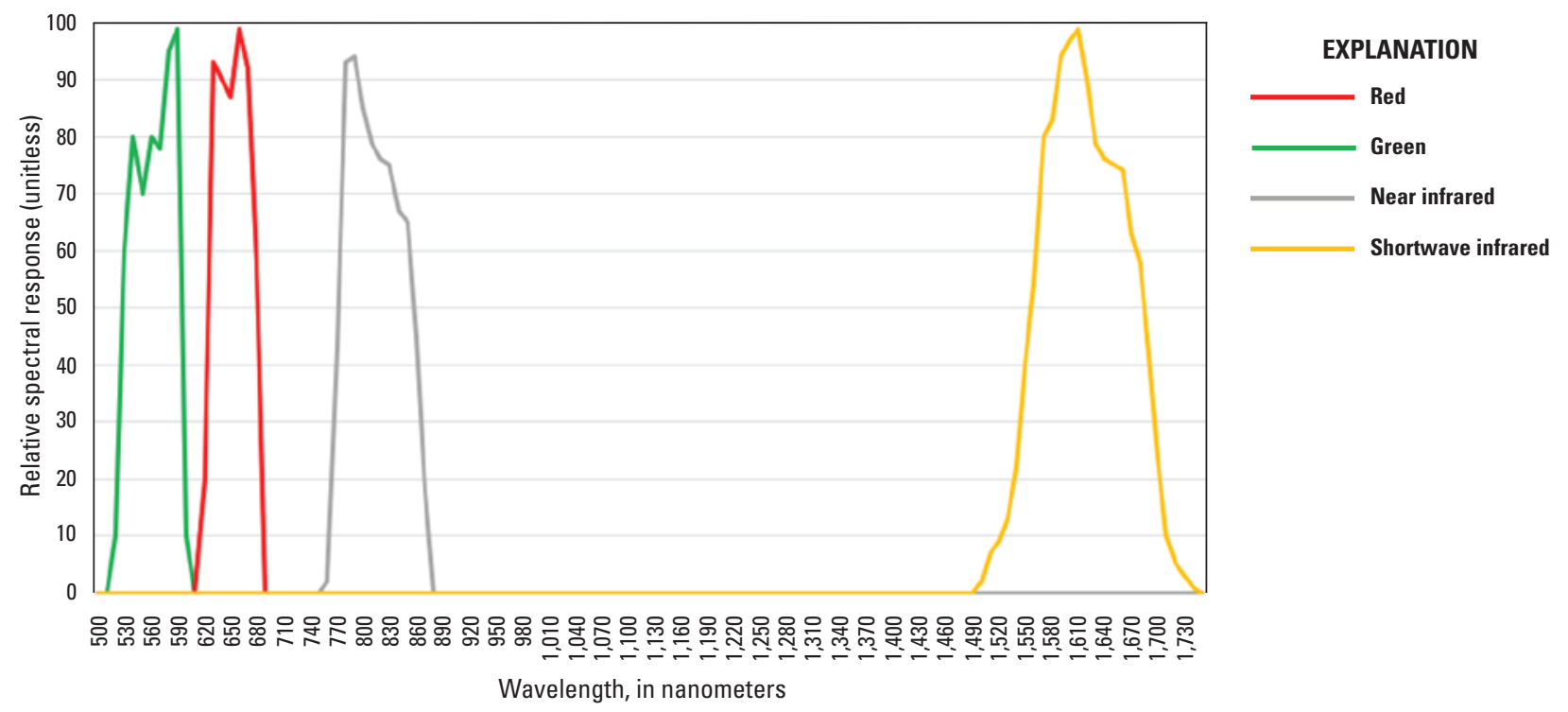

Figure 1. Resourcesat-2 Linear Imaging Self Scanning-3 relative spectral response. 
Table 3. U.S. Geological Survey measurement results.

[USGS, U.S. Geological Survey; m, meter; RMSE, root mean square error; NIR, near infrared; SWIR, shortwave infrared; LISS-3, Resourcesat-2 Linear Imaging Self Scanning-3; L8 OLI, Landsat 8 Operational Land Imager; FWHM, full width at half maximum; MTF, modulation transfer function]

Description of product

\begin{tabular}{|c|c|}
\hline \multicolumn{2}{|r|}{ Top of Atmosphere reflectance } \\
\hline \multicolumn{2}{|r|}{ USGS measurement results } \\
\hline \multicolumn{2}{|r|}{ Geometric performance (easting, northing) in meters (pixels) } \\
\hline \multirow[t]{4}{*}{ Interior (band to band) } & $\begin{array}{l}\text { Band } 2 \text { (green) } \\
\text { Mean: }-4.620 \text { to } 13.230 \mathrm{~m}(-0.154 \text { to } 0.441),-12.360 \text { to } 0.510 \mathrm{~m}(-0.412 \text { to } 0.017) \\
\text { RMSE: } 1.170 \text { to } 13.410 \mathrm{~m}(0.039 \text { to } 0.447), 1.530 \text { to } 12.450 \mathrm{~m}(0.051 \text { to } 0.415)\end{array}$ \\
\hline & $\begin{array}{l}\text { Band } 3 \text { (red) } \\
\quad \text { Mean: }-4.620 \text { to } 11.970 \mathrm{~m}(-0.154 \text { to } 0.399),-8.940 \text { to } 0.930 \mathrm{~m}(-0.298 \text { to } 0.031) \\
\text { RMSE: } 1.170 \text { to } 12.390 \mathrm{~m}(0.039 \text { to } 0.413), 1.860 \text { to } 9.120 \mathrm{~m}(0.062 \text { to } 0.304)\end{array}$ \\
\hline & $\begin{array}{l}\text { Band } 4 \text { (NIR) } \\
\text { Mean: }-4.080 \text { to } 13.230 \mathrm{~m}(-0.136 \text { to } 0.441),-9.660 \text { to } 1.500 \mathrm{~m}(-0.322 \text { to } 0.050) \\
\text { RMSE: } 1.290 \text { to } 13.410 \mathrm{~m}(0.043 \text { to } 0.447), 1.530 \text { to } 9.810 \mathrm{~m}(0.051 \text { to } 0.327)\end{array}$ \\
\hline & $\begin{array}{l}\text { Band } 5 \text { (SWIR) } \\
\text { Mean: }-4.620 \text { to } 11.970 \mathrm{~m}(-0.154 \text { to } 0.399),-12.360 \text { to } 1.500 \mathrm{~m}(-0.412 \text { to } 0.050) \\
\text { RMSE: } 3.810 \text { to } 12.150 \mathrm{~m}(0.127 \text { to } 0.405), 3.990 \text { to } 12.450 \mathrm{~m}(0.133 \text { to } 0.415)\end{array}$ \\
\hline Exterior (geometric location accuracy) & $\begin{array}{l}\text { Mean: }-27.805 \text { to } 26.578 \mathrm{~m}(-0.927 \text { to } 0.886),-35.341 \text { to }-6.286 \mathrm{~m}(-1.178 \text { to }-0.210) \\
\text { RMSE: } 0.348 \text { to } 0.939 \mathrm{~m}(10.434 \text { to } 28.177), 0.218 \text { to } 1.239 \mathrm{~m}(6.546 \text { to } 37.158)\end{array}$ \\
\hline \multicolumn{2}{|r|}{ Radiometric performance (offset, slope) } \\
\hline $\begin{array}{l}\text { Radiometric evaluation (linear regression-LISS-3 } \\
\text { versus L8 OLI reflectance) }\end{array}$ & $\begin{array}{l}\text { Band } 2-\text { Green (offset, slope): ( } 0.047 \text { to } 0.074,0.610 \text { to } 0.696) \\
\text { Band 3-Red (offset, slope): (0.039 to } 0.054,0.656 \text { to } 0.696) \\
\text { Band } 4-\text {-NIR (offset, slope): }(0.052 \text { to } 0.078,0.590 \text { to } 0.658) \\
\text { Band 5-SWIR (offset, slope): ( }-0.108 \text { to } 0.104,0.585 \text { to } 0.946)\end{array}$ \\
\hline \multicolumn{2}{|r|}{ Spatial performance } \\
\hline Spatial performance measurement & $\begin{array}{l}\text { Band 2-Green: FWHM }=2.55 \text { pixels; } \text { MTF at Nyquist }=0.028 \\
\text { Band 3-Red: FWHM }=2.52 \text { pixels; MTF at Nyquist }=0.018 \\
\text { Band 4-NIR: FWHM }=2.54 \text { pixels; MTF at Nyquist }=0.022 \\
\text { Band 5-SWIR: FWHM }=2.57 \text { pixels; MTF at Nyquist }=0.018\end{array}$ \\
\hline
\end{tabular}




\section{Analysis}

This section describes the geometric, radiometric, and spatial performance of LISS-3.

\section{Geometric Performance}

This geometric performance for LISS-3 is characterized in terms of the interior (band-to-band alignment) and exterior (geometric location accuracy) geometric analysis results.

\section{Interior (Band to Band)}

The band-to-band alignment analysis was completed using the EROS System Characterization (EROSSC) software on three separate images over the United States. Band combinations were registered against each other to determine the mean error, STDDEV, and RMSE, as listed in table 4 with results represented in pixels at a 30-meter (m) GSD (the LISS-3 image was resampled to $30 \mathrm{~m}$ ). Geometric error maps for each assessed band combination over the New Mexico image, as well as the corresponding histogram graphs, are shown in figures $2-5$. The geometric error maps indicate the directional shift and relative magnitude of the shift, and the histogram and error distribution indicate frequency of observed mean error measurements within the image. Together, the interior and exterior geometric analysis results, as reported in the "Interior (Band to Band)" and "Exterior (Geometric Location Accuracy)" sections, provide a comprehensive assessment of geometric accuracy.

\section{Exterior (Geometric Location Accuracy)}

For this analysis, band 2 (green) of the LISS-3 data was compared against the corresponding band from three Landsat 8 OLI images over sites in the United States using the EROSSC software. Conjugate points in the reference and search images were identified automatically and refined using similarity measures such as normalized cross-correlation metrics, and the mean error, STDDEV, and RMSE results are listed in table 5 with results represented in pixels (and meters) at a 30-m GSD (LISS-3 was resampled to $30 \mathrm{~m}$ ). For each of the three images, geometric error maps showing the directional shift and relative magnitude of the shift, when compared with the Landsat 8 OLI, along with the corresponding histogram and error distribution, are provided in figures $6-11$. The Landsat 8 OLI imagery had a control uncertainty of about $8 \mathrm{~m}$.

Table 4. Band-to-band registration error (in pixels).

[ID, identifier; STDDEV, standard deviation; RMSE, root mean square error]

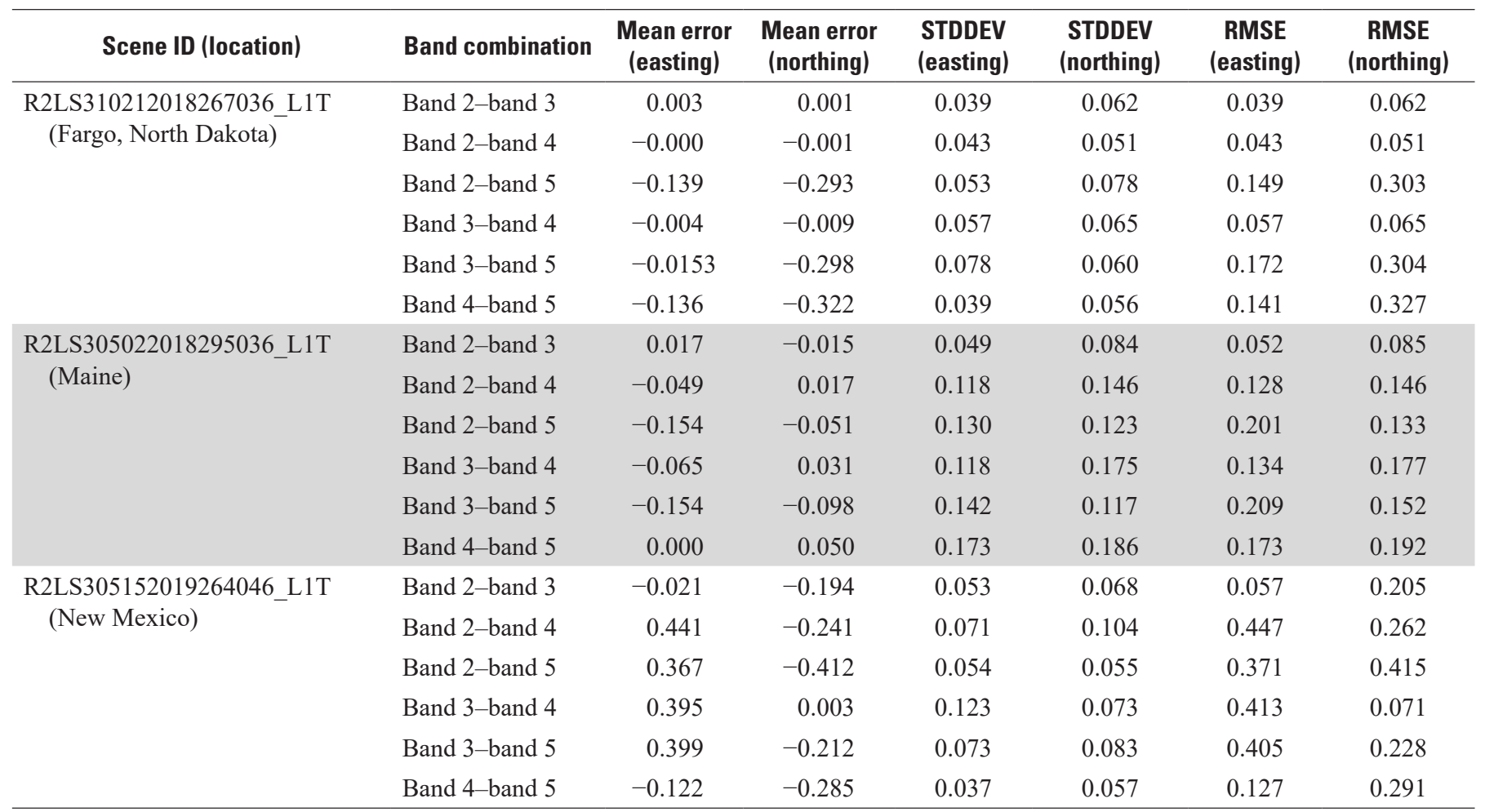




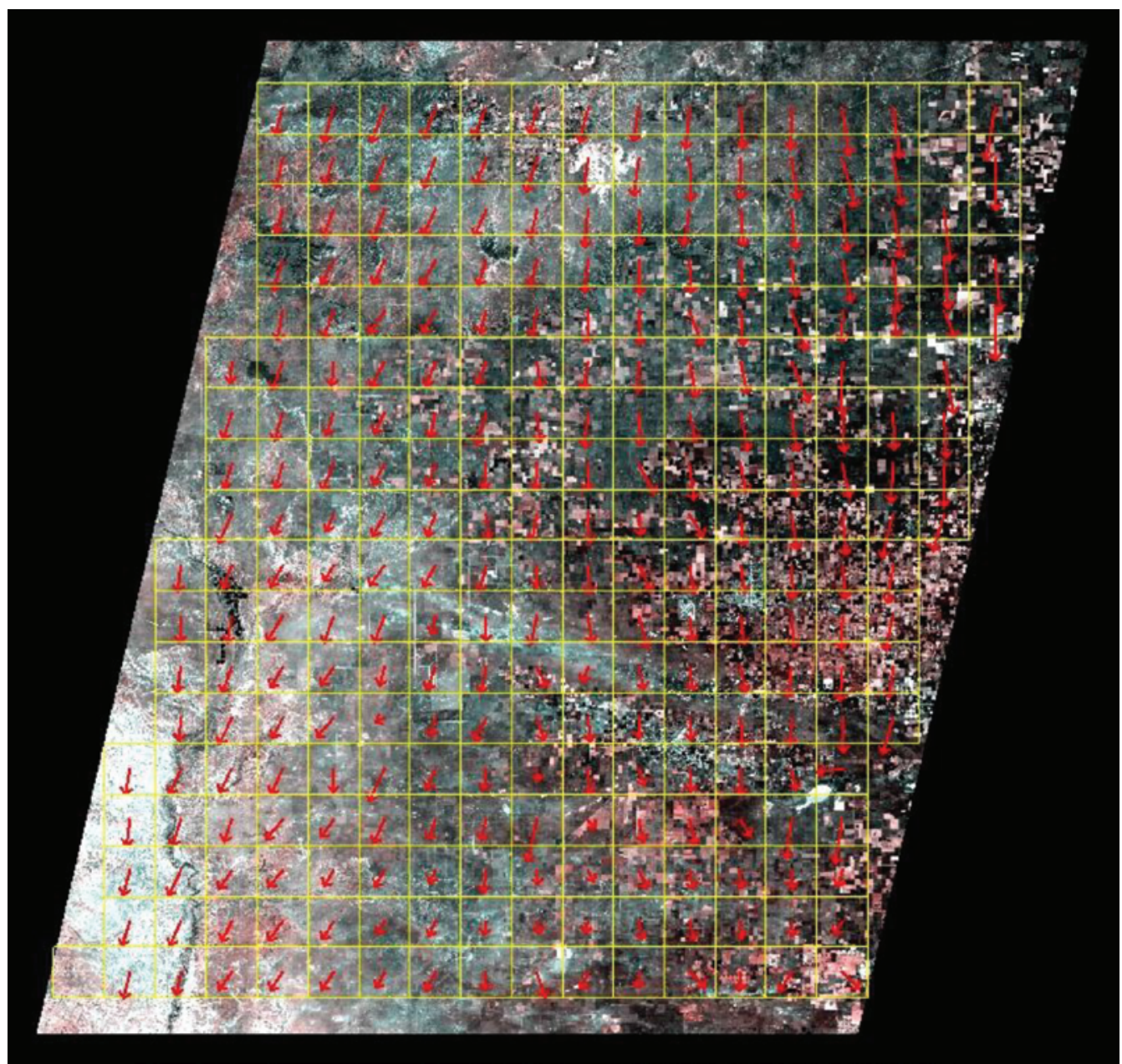

EXPLANATION

$\rightarrow$ Easting and northing error

- Grid

Figure 2. Band 2 (green) to band 3 (red) geometric error map for New Mexico. 

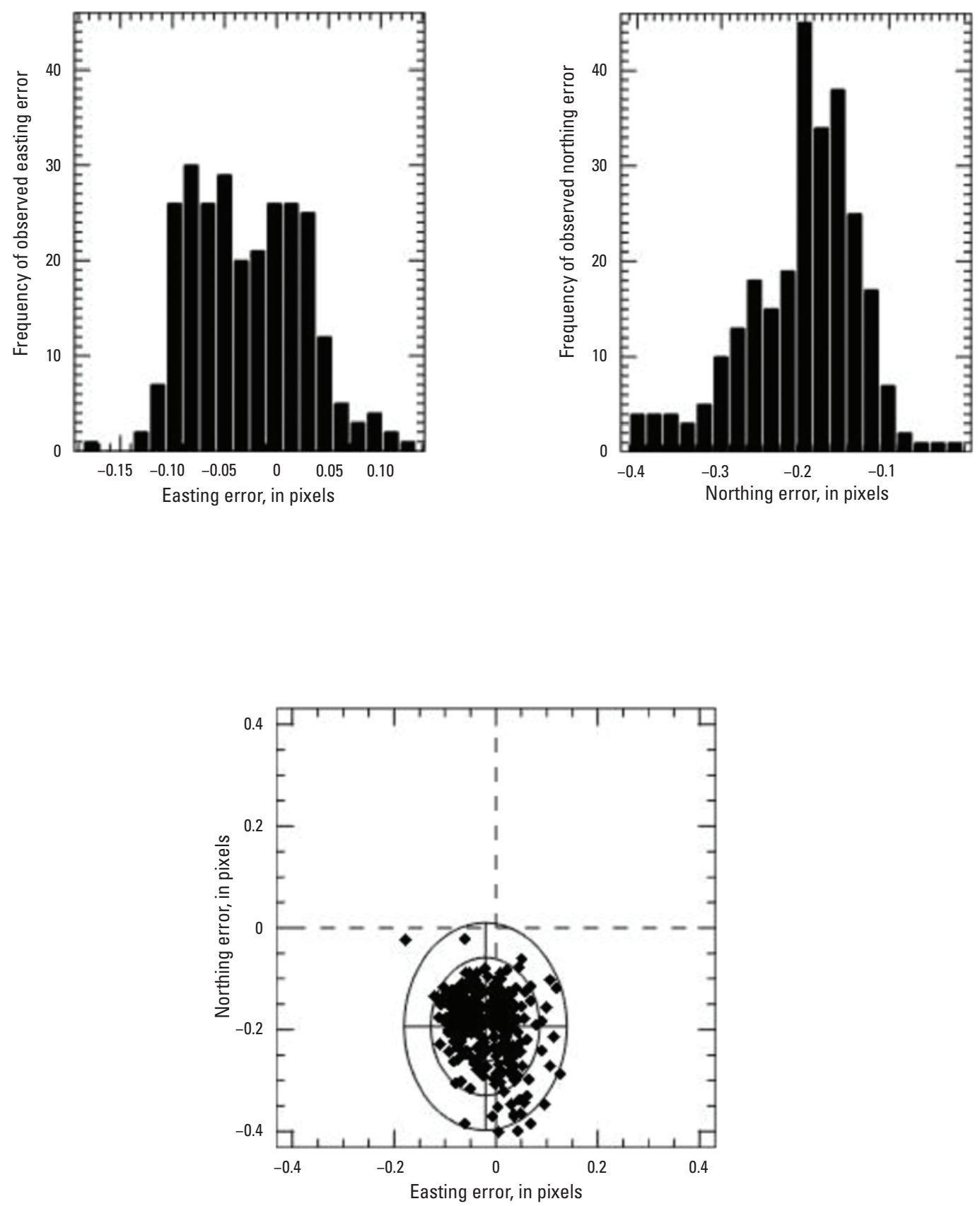

Figure 3. Band 2 (green) to band 3 (red) geometric error histogram (upper) and error distribution (lower) for New Mexico. 


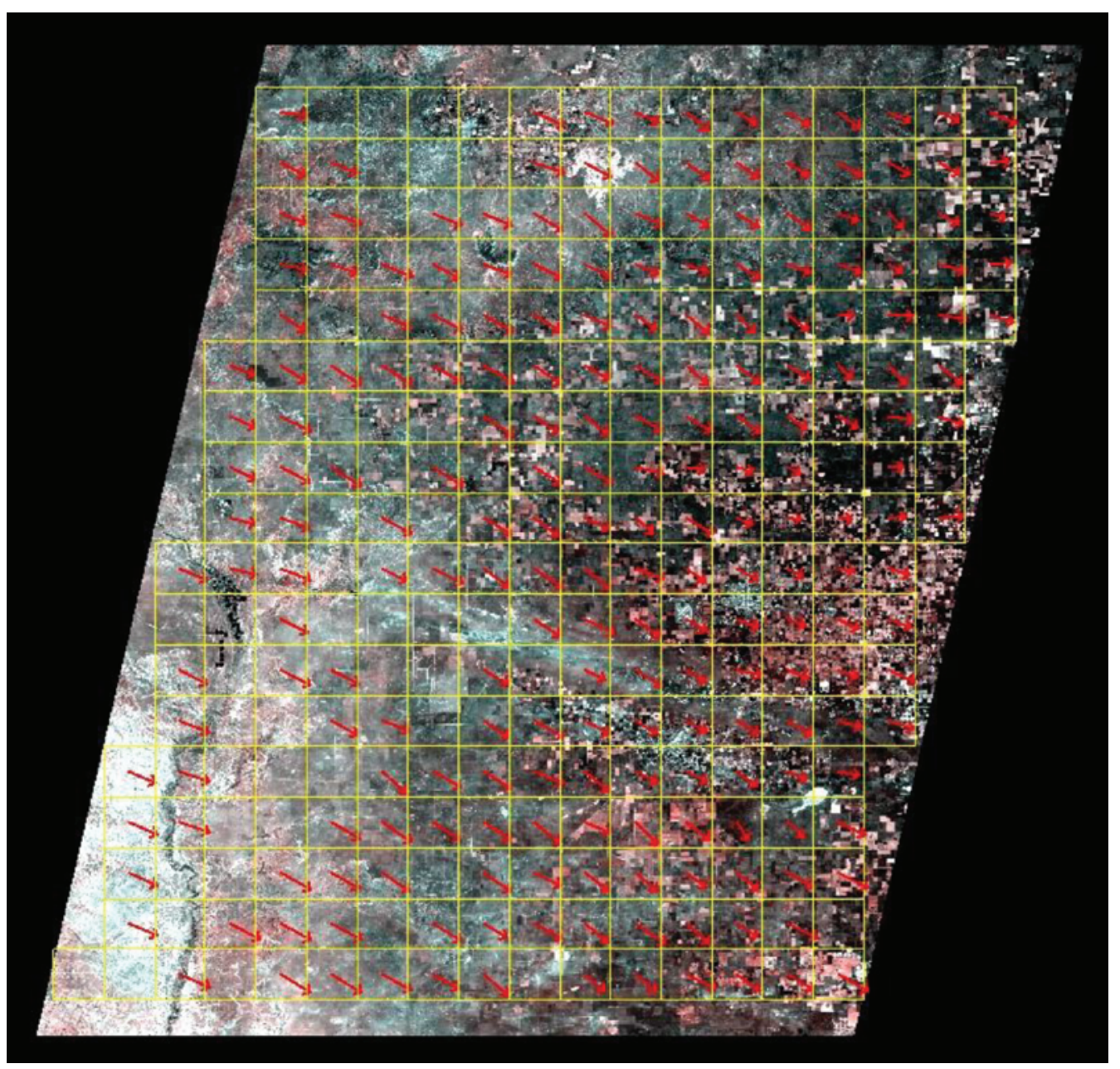

EXPLANATION

$\rightarrow$ Easting and northing error Grid

Figure 4. Band 3 (red) to band 5 (shortwave infrared) geometric error map for New Mexico. 

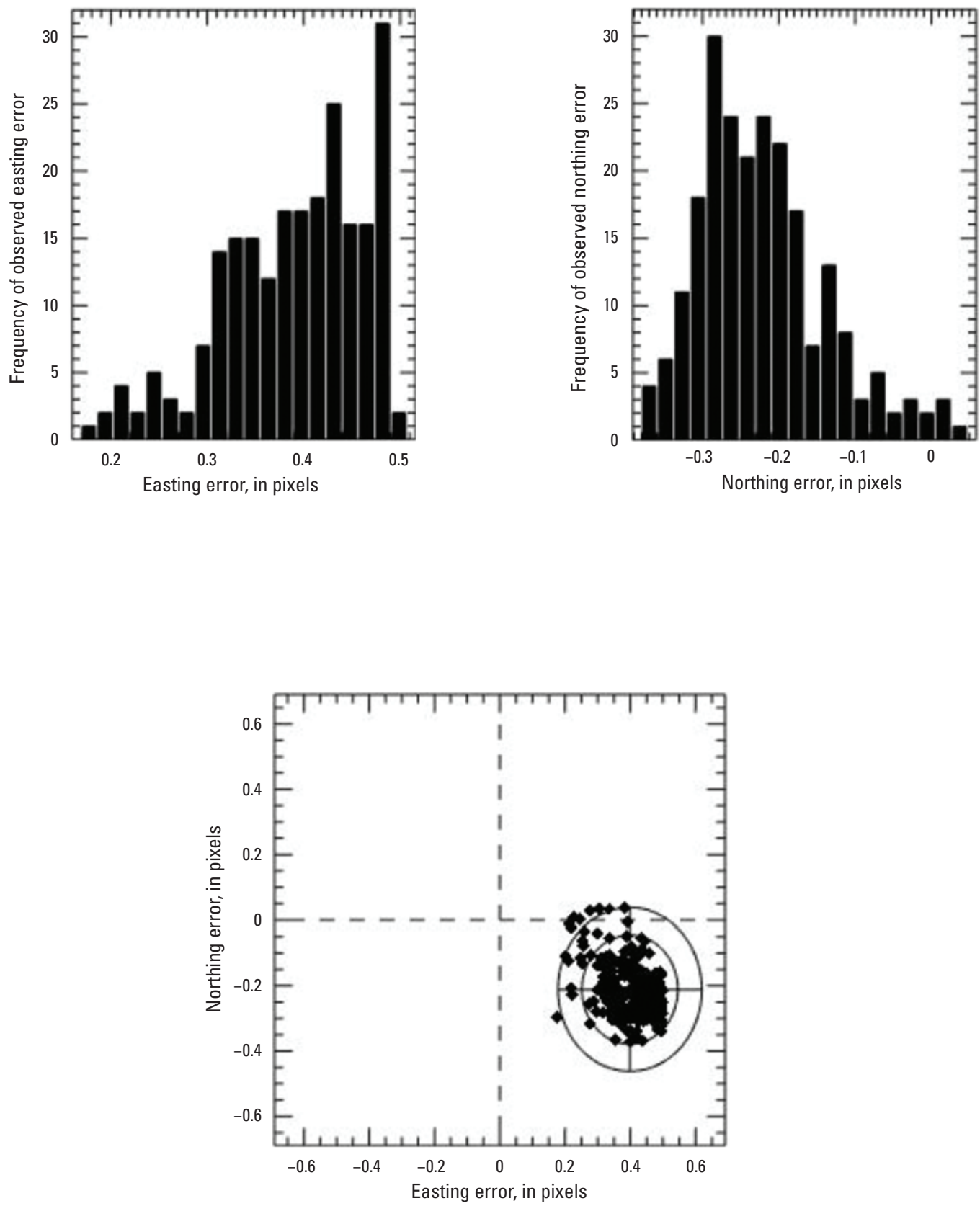

Figure 5. Band 3 (red) to band 5 (shortwave infrared) geometric error histogram (upper) and error distribution (lower) for New Mexico. 
Table 5. Geometric error of Resourcesat-2 Linear Imaging Self Scanning-3 relative to Landsat 8 Operational Land Imager.

[ID, identifier; STDDEV, standard deviation; RMSE, root mean square error; m, meter]

\begin{tabular}{|c|c|c|c|c|c|c|}
\hline Scene ID (location) & $\begin{array}{c}\text { Mean error } \\
\text { (easting) }\end{array}$ & $\begin{array}{l}\text { Mean error } \\
\text { (northing) }\end{array}$ & $\begin{array}{l}\text { STDDEV } \\
\text { (easting) }\end{array}$ & $\begin{array}{c}\text { STDDEV } \\
\text { (northing) }\end{array}$ & $\begin{array}{c}\text { RMSE } \\
\text { (easting) }\end{array}$ & $\begin{array}{c}\text { RMSE } \\
\text { (northing) }\end{array}$ \\
\hline $\begin{array}{l}\text { R2LS310212018267036_L1TLC08_L1TP_03 } \\
\text { 0027_20181021_20200830_02_T1 } \\
\text { (Fargo, North Dakota) }\end{array}$ & $\begin{array}{c}-0.311 \text { pixel } \\
(-9.342 \mathrm{~m})\end{array}$ & $\begin{array}{c}-0.209 \text { pixel } \\
(-6.286 \mathrm{~m})\end{array}$ & $\begin{array}{c}0.156 \text { pixel } \\
(4.667 \mathrm{~m})\end{array}$ & $\begin{array}{c}0.061 \text { pixel } \\
(1.833 \mathrm{~m})\end{array}$ & $\begin{array}{l}0.348 \text { pixel } \\
(10.434 \mathrm{~m})\end{array}$ & $\begin{array}{c}0.218 \text { pixel } \\
(6.546 \mathrm{~m})\end{array}$ \\
\hline $\begin{array}{l}\text { R2LS305022018295036_L1TLC08_L1TP_01 } \\
\text { 0028_20180502_20200901_02_T1 } \\
\text { (Maine) }\end{array}$ & $\begin{array}{l}0.885 \text { pixel } \\
(26.578 \mathrm{~m})\end{array}$ & $\begin{array}{c}-1.178 \text { pixels } \\
(-35.341 \mathrm{~m})\end{array}$ & $\begin{array}{c}0.254 \text { pixel } \\
(7.615 \mathrm{~m})\end{array}$ & $\begin{array}{l}0.383 \text { pixel } \\
(11.489 \mathrm{~m})\end{array}$ & $\begin{array}{l}0.921 \text { pixel } \\
(27.646 \mathrm{~m})\end{array}$ & $\begin{array}{c}1.238 \text { pixels } \\
(37.158 \mathrm{~m})\end{array}$ \\
\hline $\begin{array}{l}\text { R2LS305152019264046_L1TLC08_L1TP_03 } \\
\text { 2036_20190515_20200828_02_T1 } \\
\text { (New Mexico) }\end{array}$ & $\begin{array}{l}-0.926 \text { pixel } \\
(-27.805 \mathrm{~m})\end{array}$ & $\begin{array}{l}-0.567 \text { pixel } \\
(-17.014 \mathrm{~m})\end{array}$ & $\begin{array}{c}0.152 \text { pixel } \\
(4.569 \mathrm{~m})\end{array}$ & $\begin{array}{c}0.288 \text { pixel } \\
(8.652 \mathrm{~m})\end{array}$ & $\begin{array}{l}0.939 \text { pixel } \\
(28.177 \mathrm{~m})\end{array}$ & $\begin{array}{l}0.636 \text { pixel } \\
(19.082 \mathrm{~m})\end{array}$ \\
\hline
\end{tabular}




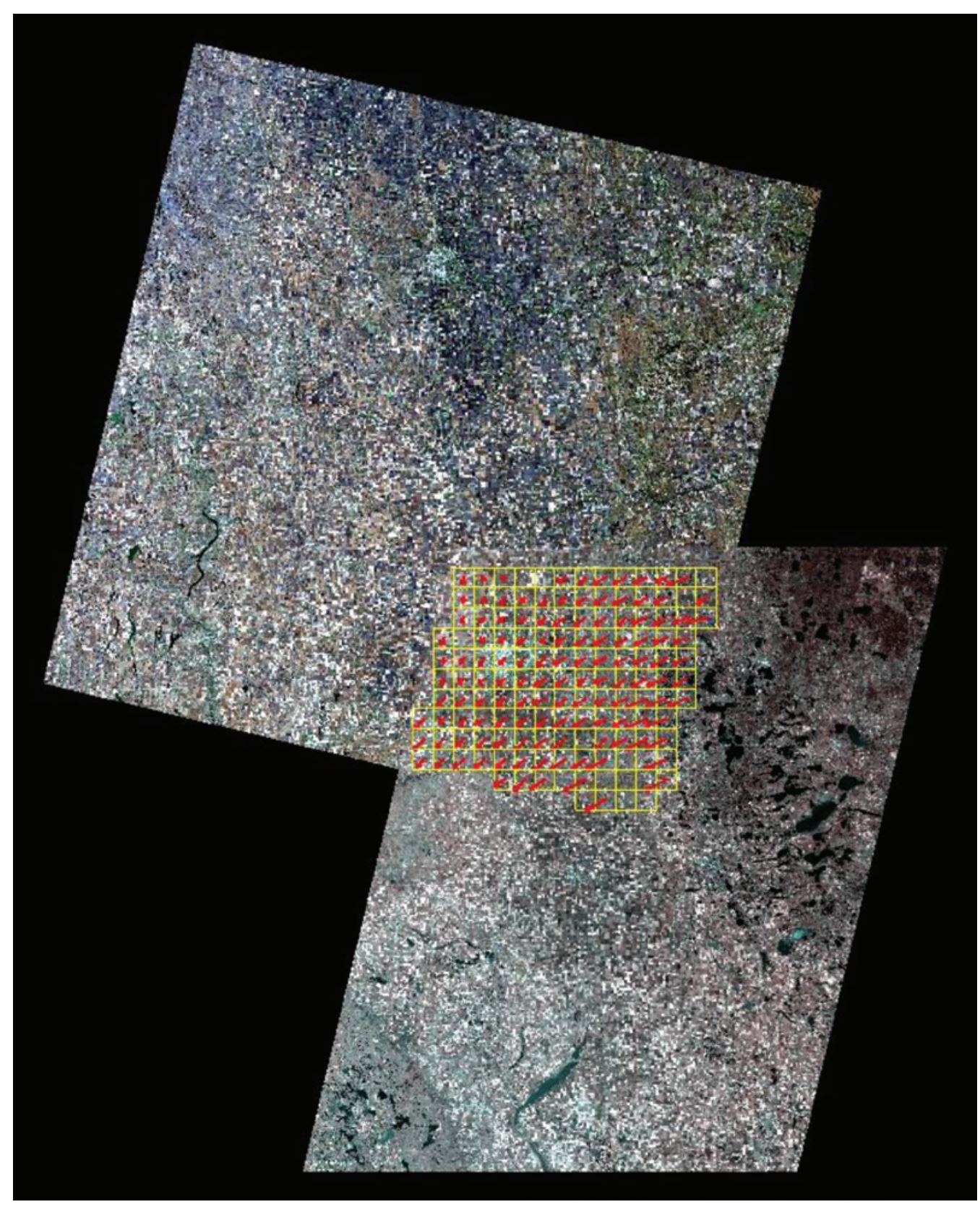

EXPLANATION

$\rightarrow$ Easting and northing error Grid

Figure 6. Relative geometric error for Landsat 8 Operational Land Imager and Resourcesat-2 Linear Imaging Self Scanning-3 for Fargo, North Dakota. 

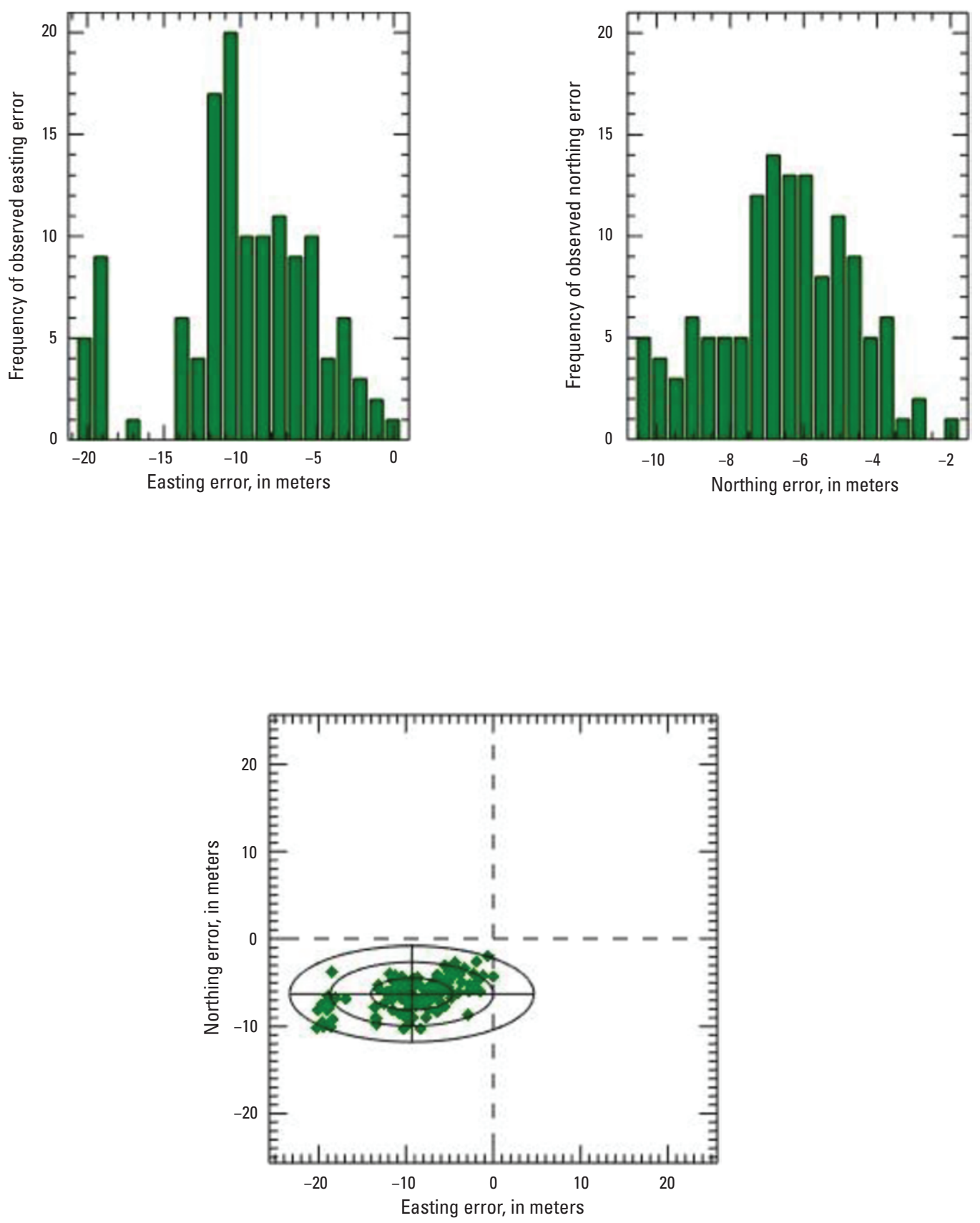

Figure 7. Relative geometric error histogram (upper) and error distribution (lower) for Fargo, North Dakota. 


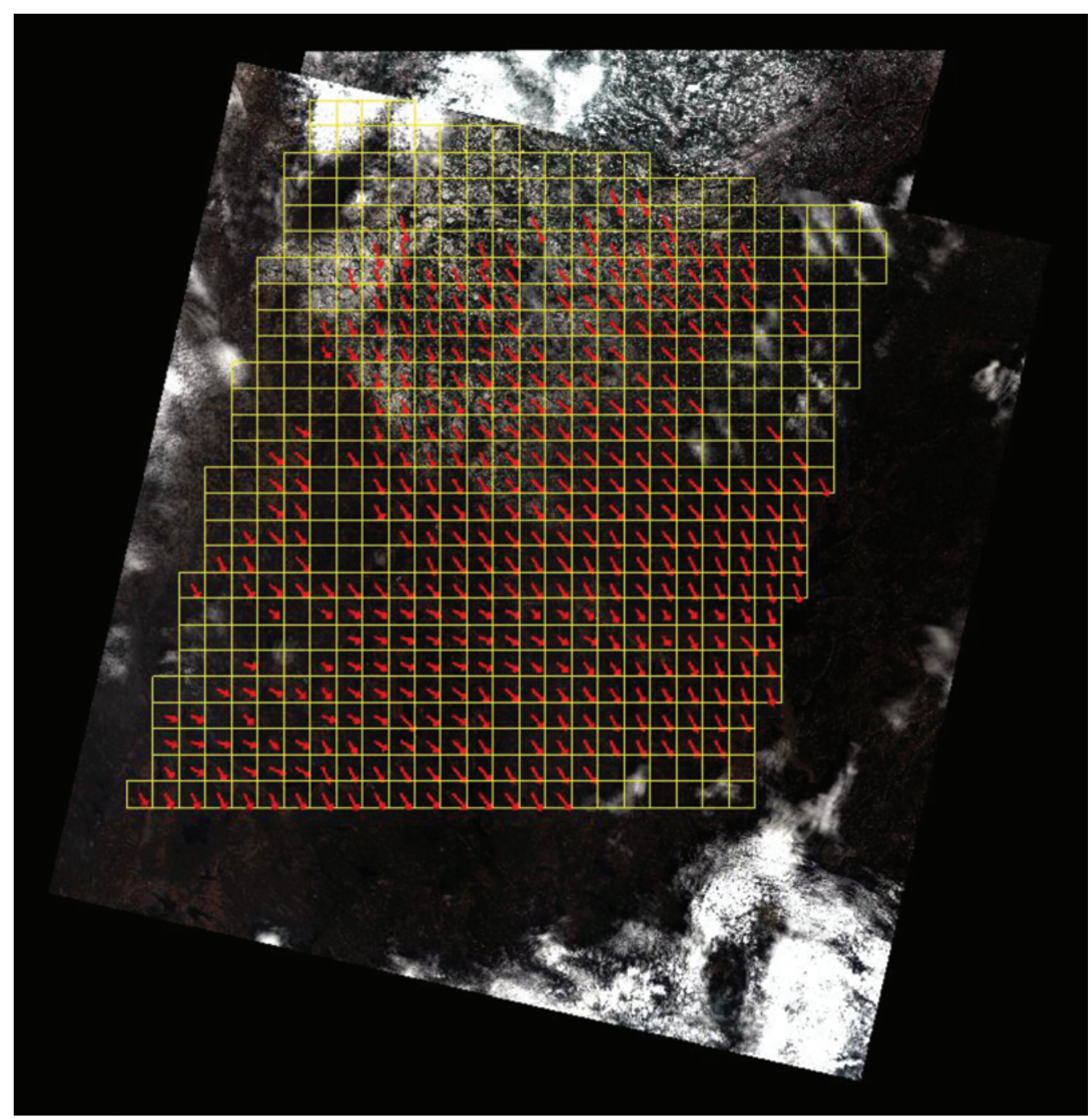

EXPLANATION

$\rightarrow$ Easting and northing error

Grid

Figure 8. Relative geometric error for Landsat 80 0perational Land Imager and Resourcesat-2 Linear Imaging Self Scanning-3 for Maine. 

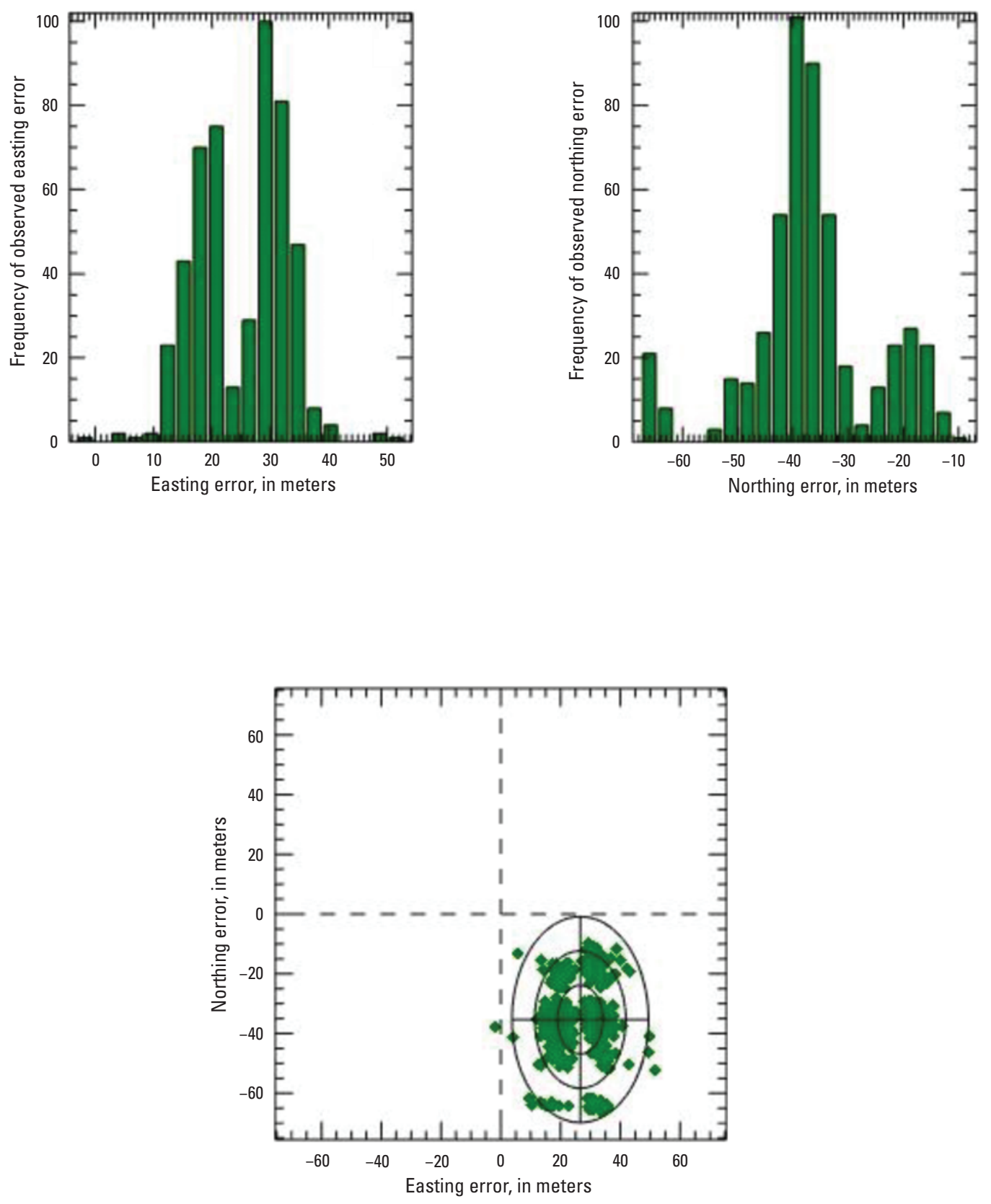

Figure 9. Relative geometric error histogram (upper) and error distribution (lower) for Maine. 


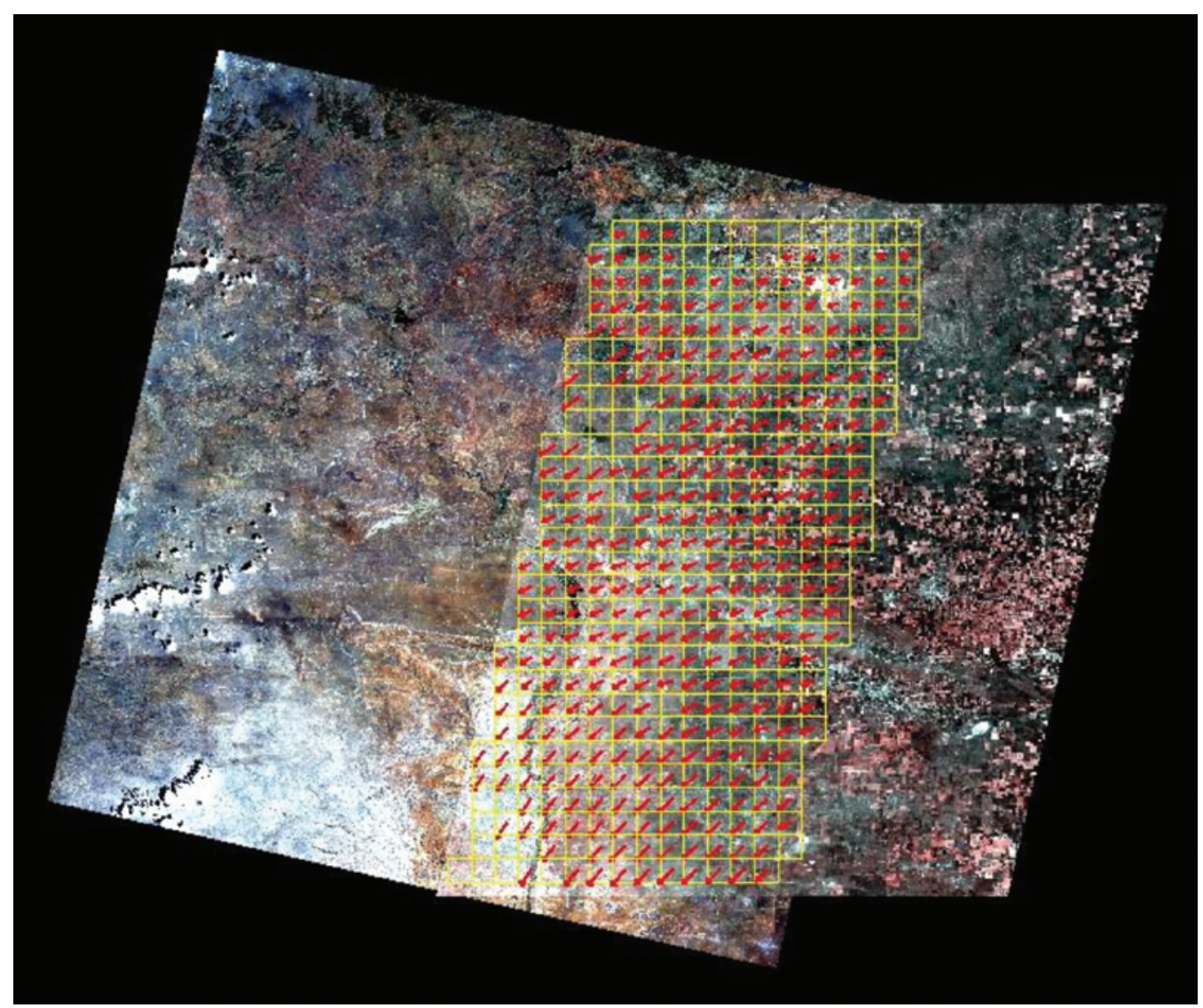

EXPLANATION

$\rightarrow$ Easting and northing error Grid

Figure 10. Relative geometric error for Landsat 8 Operational Land Imager and Resourcesat-2 Linear Imaging Self Scanning-3 for New Mexico. 

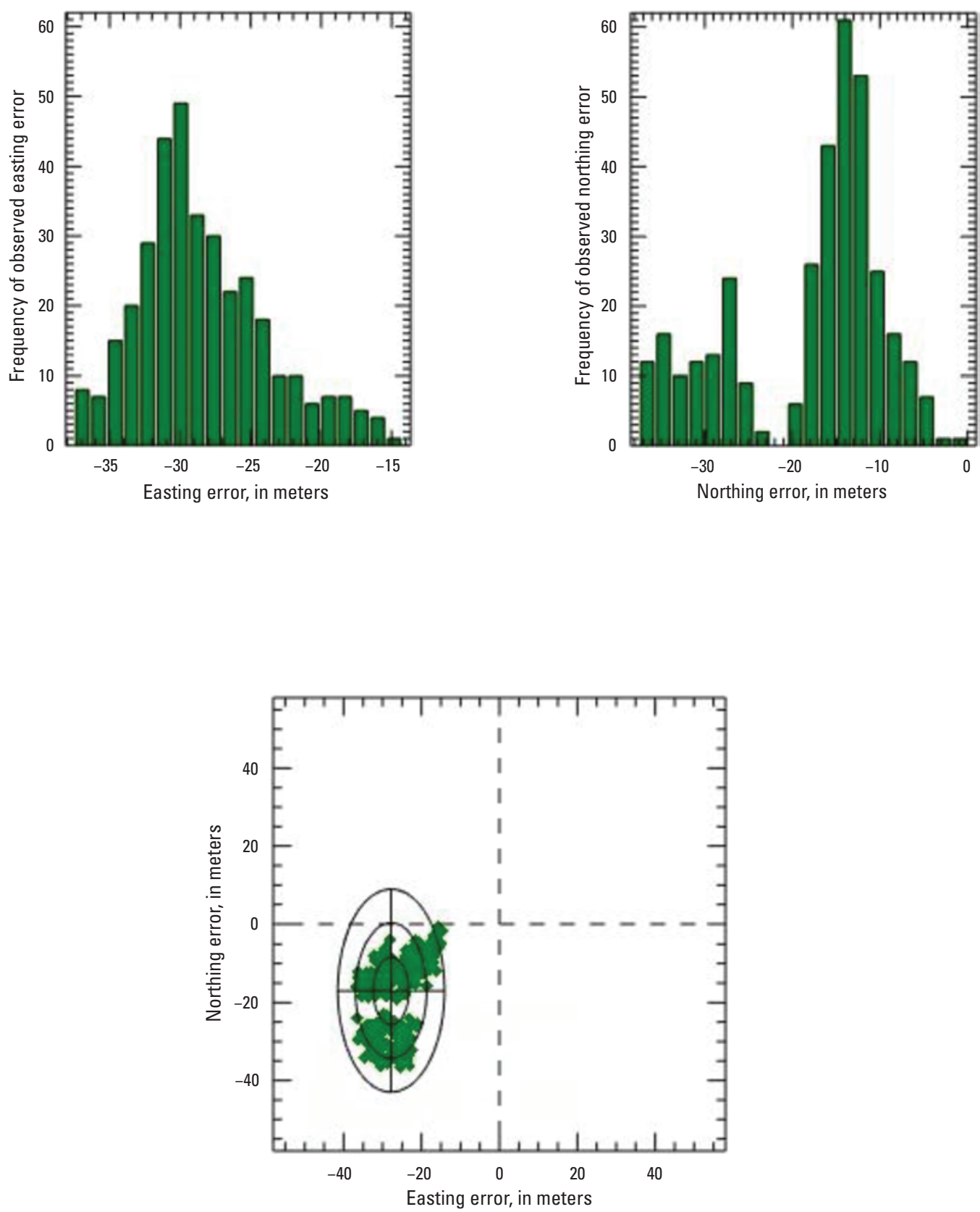

Figure 11. Relative geometric error histogram (upper) and error distribution (lower) for New Mexico.

\section{Radiometric Performance}

For this analysis, cloud-free regions of interest were selected within three near-coincident LISS-3 and Landsat 8 OLI scene pairs using the EROSSC software. Once the relative georeferencing error between Landsat 8 OLI and Resourcesat-2 LISS-3 has been corrected, Top of Atmosphere reflectance values from the two sensors are extracted. The scatterplot (fig. 12) is drawn in a way that the $\mathrm{x}$-axis is the reference sensor and the $y$-axis is the comparison sensor.
The linear regression, thus, represents Top of Atmosphere reflectance relative to that of the reference sensor. Ideally, the slope should be near unity and the offset should be near zero. For instance, if the slope is greater than unity, that means the comparison sensor has a tendency to overestimate Top of Atmosphere reflectance compared to the reference sensor.

Top of Atmosphere reflectance comparison results are listed in table 6. A band-by-band graphical comparison between the LISS-3 image over Maine, when compared with the corresponding Landsat 8 OLI band, is shown in figure 12 . 

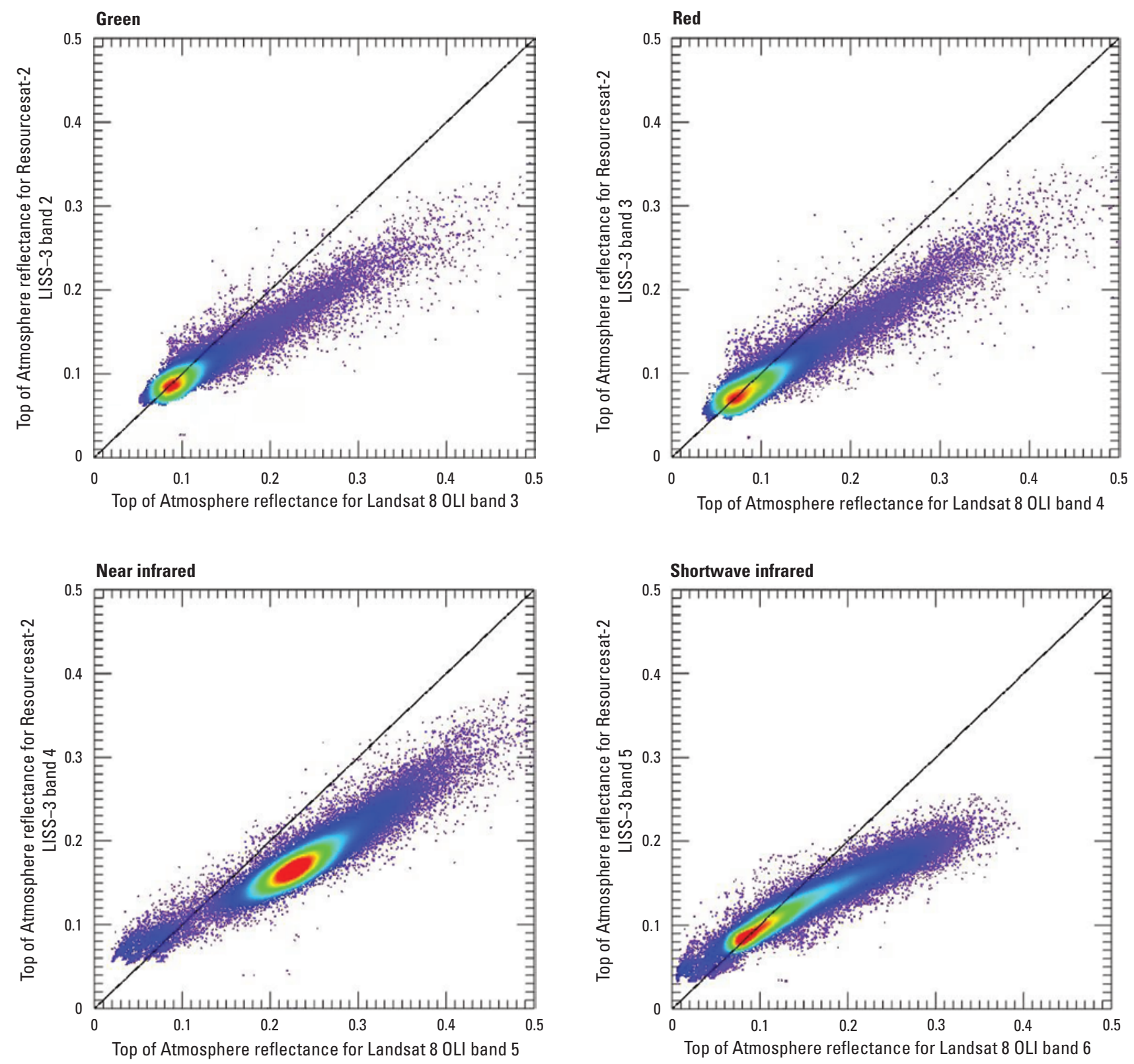

Figure 12. Top of Atmosphere reflectance comparison for Landsat 8 Operational Land Imager (OLI) and Resourcesat-2 Linear Imaging Self Scanning-3 (LISS-3; Maine). 
Table 6. Top of Atmosphere reflectance comparison of Resourcesat-2 Linear Imaging Self Scanning-3 against Landsat 8 Operational Land Imager.

[ID, identifier; NIR, near infrared; SWIR, shortwave infrared; \%, percent; $R^{2}$, coefficient of determination]

\begin{tabular}{llcrrr}
\hline \multicolumn{1}{c}{ Scene ID (location) } & \multicolumn{1}{c}{ Statistics } & Band 2-Green & Band 3-Red & Band 4-NIR & Band 5-SWIR \\
\hline R2LS310212018267036_L1TLC08 & Uncertainty (\%) & 8.750 & 11.220 & 15.020 & 13.410 \\
L1TP_030027_20181021_202008 & $R^{2}$ & 0.926 & 0.939 & 0.937 & 0.631 \\
30_02_T1 & Radical offset & -0.045 & -0.026 & -0.046 & 0.080 \\
(Fargo, North Dakota) & Radical slope & 1.639 & 1.525 & 1.695 & 1.105 \\
R2LS305022018295036_L1TLC08 & Uncertainty (\%) & 13.340 & 17.470 & 12.700 & 24.170 \\
L1TP_010028_20180502_202009 & $R^{2}$ & 0.793 & 0.852 & 0.836 & 0.877 \\
01_02_T1 & Radical offset & -0.033 & -0.027 & -0.033 & -0.061 \\
(Maine) & Radical slope & 1.437 & 1.737 & 1.573 & 1.710 \\
R2LS305152019264046_L1TLC08- & Uncertainty (\%) & 4.49 & 6.48 & 5.33 & 5.46 \\
L1TP_032036_20190515_202008 & $R^{2}$ & 0.904 & 0.908 & 0.894 & 0.665 \\
28_02_T1 & Radical offset & -0.045 & -0.037 & -0.045 & 0.102 \\
(New Mexico) & Radical slope & 1.544 & 1.455 & 1.519 & 1.057 \\
\hline
\end{tabular}

\section{Spatial Performance}

For this analysis, edge spread and line spread functions were calculated using the EROSSC software, with resulting relative edge response, full width at half maximum, and modulation transfer function at Nyquist frequency analysis output, as listed in table 7. The area selected within the Fargo, North Dakota, scene for spatial analysis is shown in figure 13.
For spatial analysis, we usually prefer to select edges along human-made features; however, at the Resourcesat- 2 scale (23.5-m GSD) only agricultural fields, which have fairly straight edges, were large enough. Therefore, we decided to look at agricultural fields and selected a bare field that was spectrally different in all four bands compared to the adjacent field. The yellow box in figure 13 shows the edge transect region of interest.

Table 7. Spatial performance of Resourcesat-2 Linear Imaging Self Scanning-3.

[RER, relative edge response; FWHM, full width at half maximum; MTF, modulation transfer function; NIR, near infrared; SWIR, shortwave infrared]

\begin{tabular}{lcccc}
\hline & Spatial analysis & RER & FWHM (pixels) & MTF at Nyquist \\
\hline Band 2-green & 0.42 & 2.55 & 0.028 \\
Band 3-red & 0.42 & 2.52 & 0.018 \\
Band 4-NIR & 0.42 & 2.54 & 0.022 \\
Band 5-SWIR & 0.41 & 2.57 & 0.018 \\
\hline
\end{tabular}




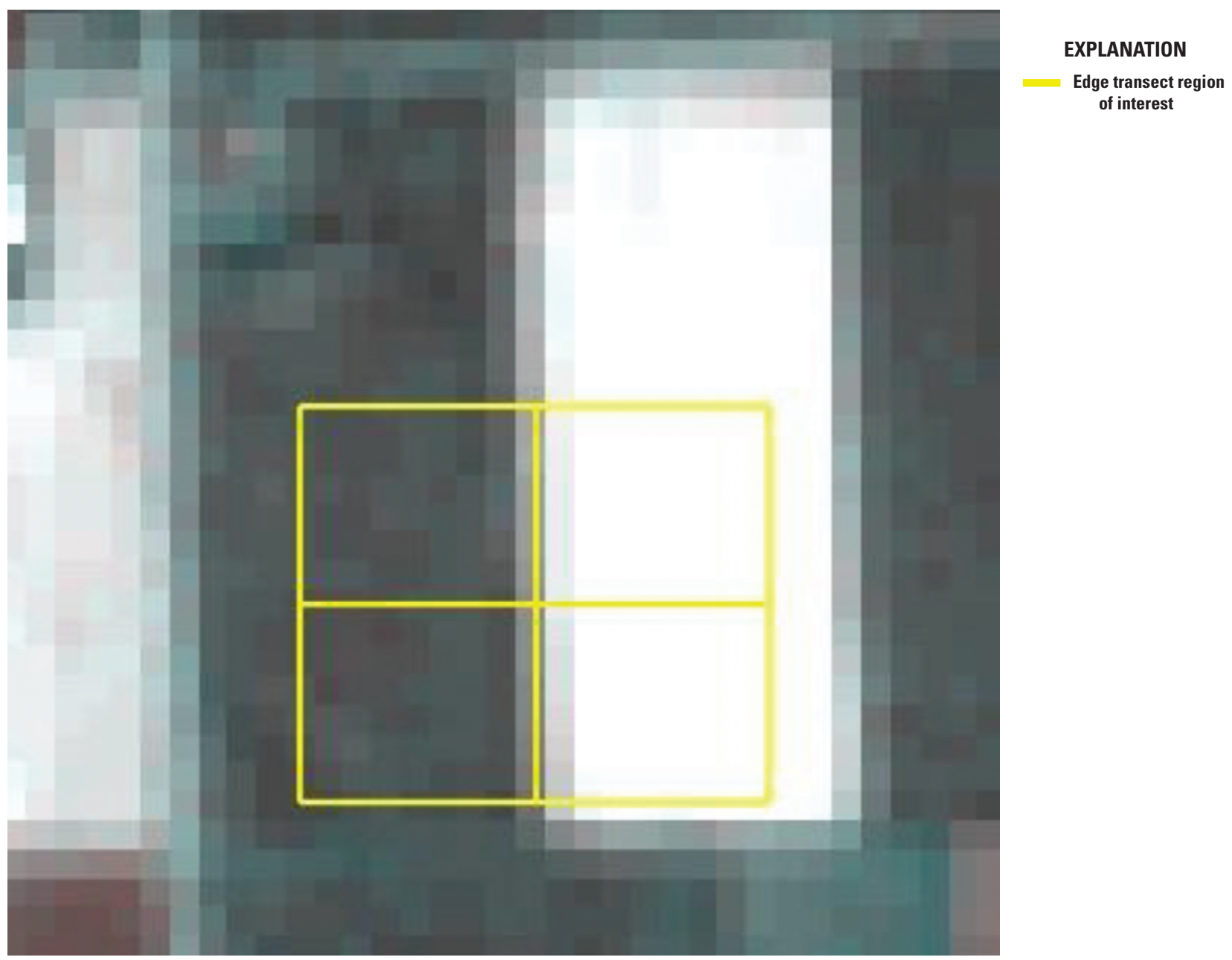

Figure 13. Resourcesat-2 Linear Imaging Self Scanning-3 image region of interest selected for spatial analysis (Fargo, North Dakota).

The band 2 (green) results are shown in figures 14 and 15. In figure 14, the dotted lines with diamond symbols are the raw transects. The green line is the middle transect, where the red dots are the region of the curve that is used for alignment. The lower plot in figure 14 is the aligned curve, and the green line represents the edge spread function. In the upper plot in figure 15, the white curve is the edge spread function, and the red line segment shows the relative edge response; the green curve is the line spread function, and the horizontal white line segment represents the full width at half maximum. The lower plot in figure 15 is the modulation transfer function up to Nyquist frequency (0.5), and the dashed line shows the frequency corresponding to the 50-percent modulation transfer function value. The results for band 3 (red) are shown in figures 16 and 17, the results for band 4 (near infrared) are shown in figures 18 and 19, and the results for band 5 (shortwave infrared) are shown in figures 20 and 21. 

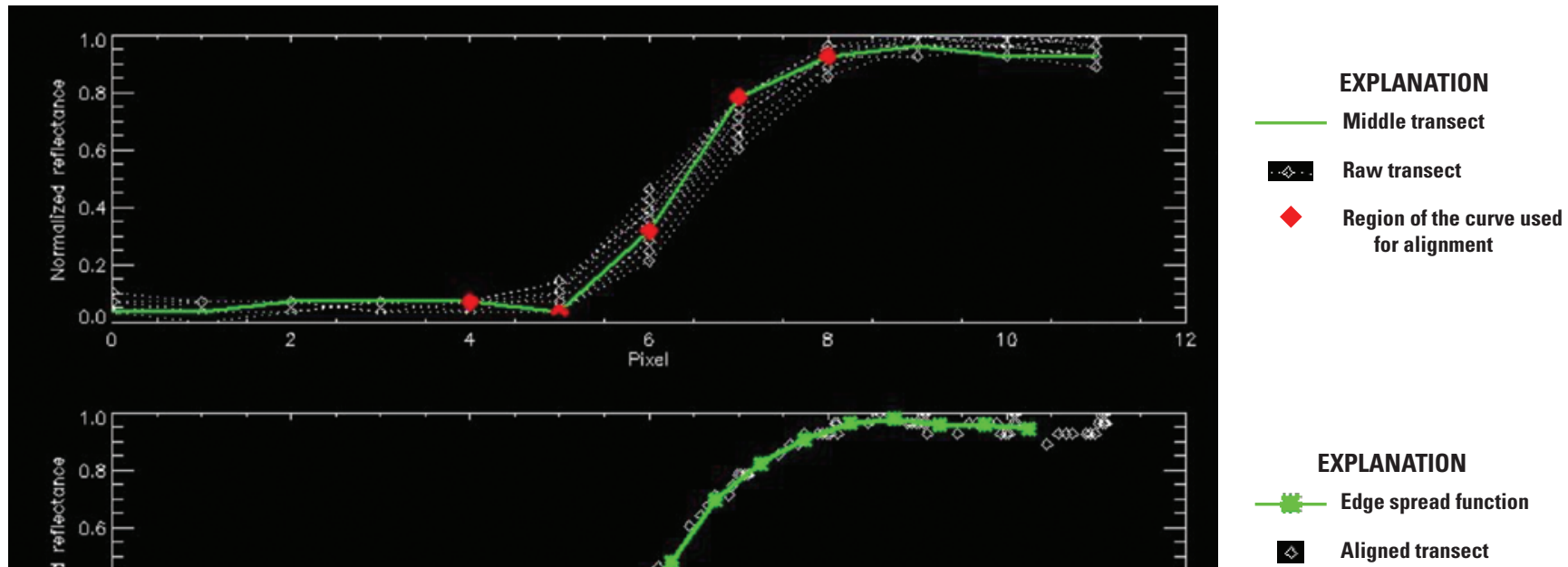

Middle transect

\&. Raw transect

Region of the curve used for alignment

EXPLANATION

-ii:- Edge spread function

$\Delta$ Aligned transect

EXPLANATION

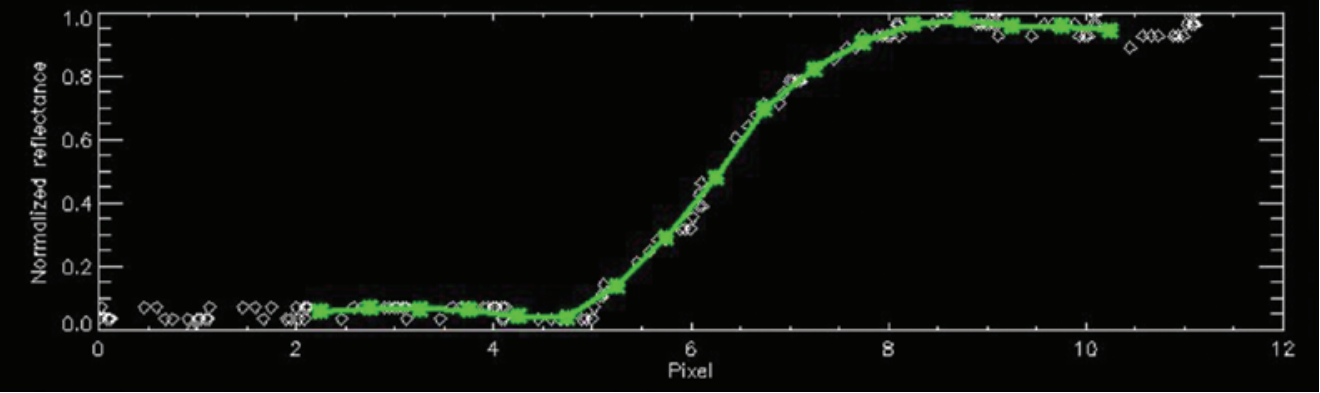

Figure 14. Band 2 (green) raw edge transects (upper) and aligned transects (lower).

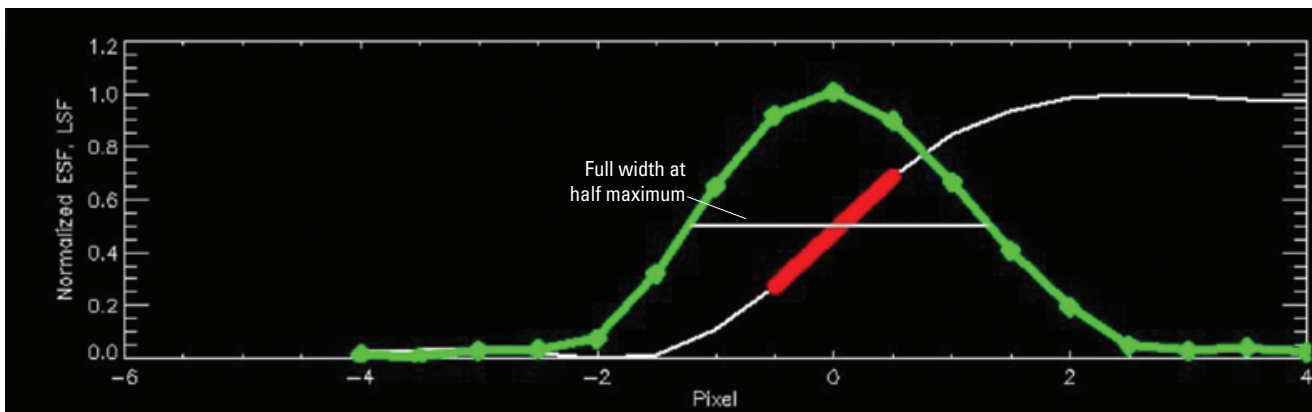

\section{EXPLANATION \\ - Line spread function \\ Relative edge response \\ Edge spread function}

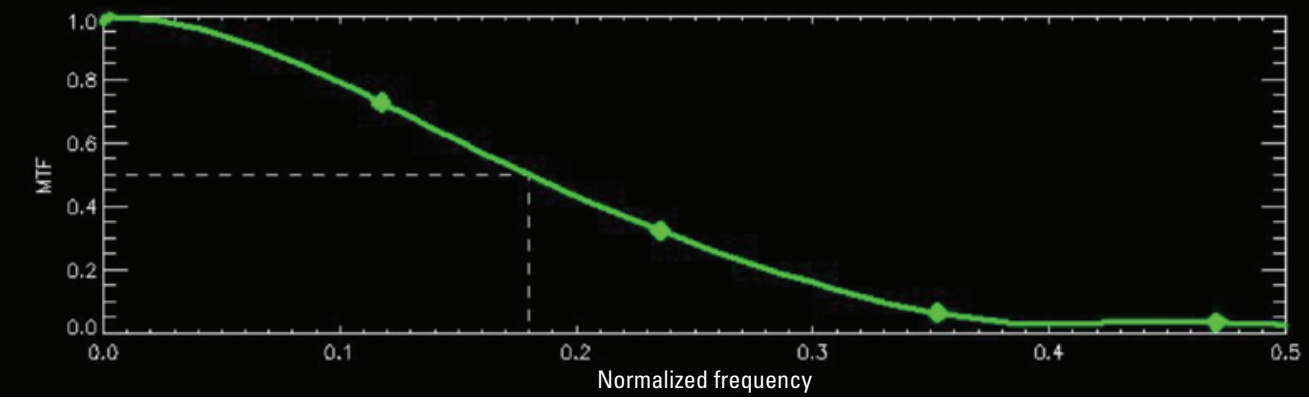

\section{EXPLANATION}

- Modulation transfer function

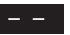

Frequency corresponding to the 50-percent

modulation transfer

function value

Figure 15. Band 2 (green) edge spread function (ESF) and line spread function (LSF; upper) and modulation transfer function (MTF; lower). 


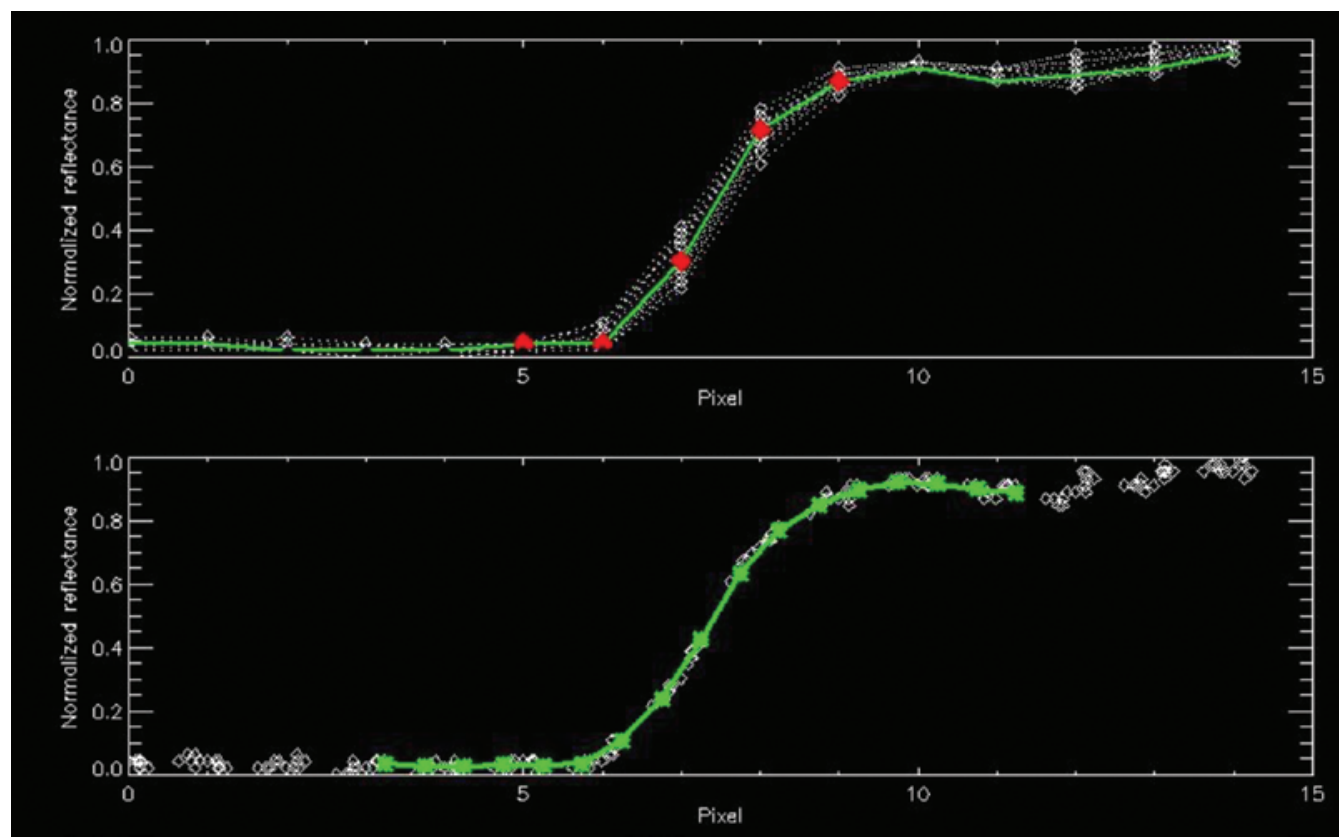

EXPLANATION

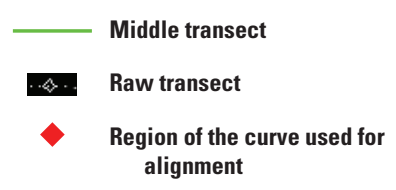

Figure 16. Band 3 (red) raw edge transects (upper) and aligned transects (lower).
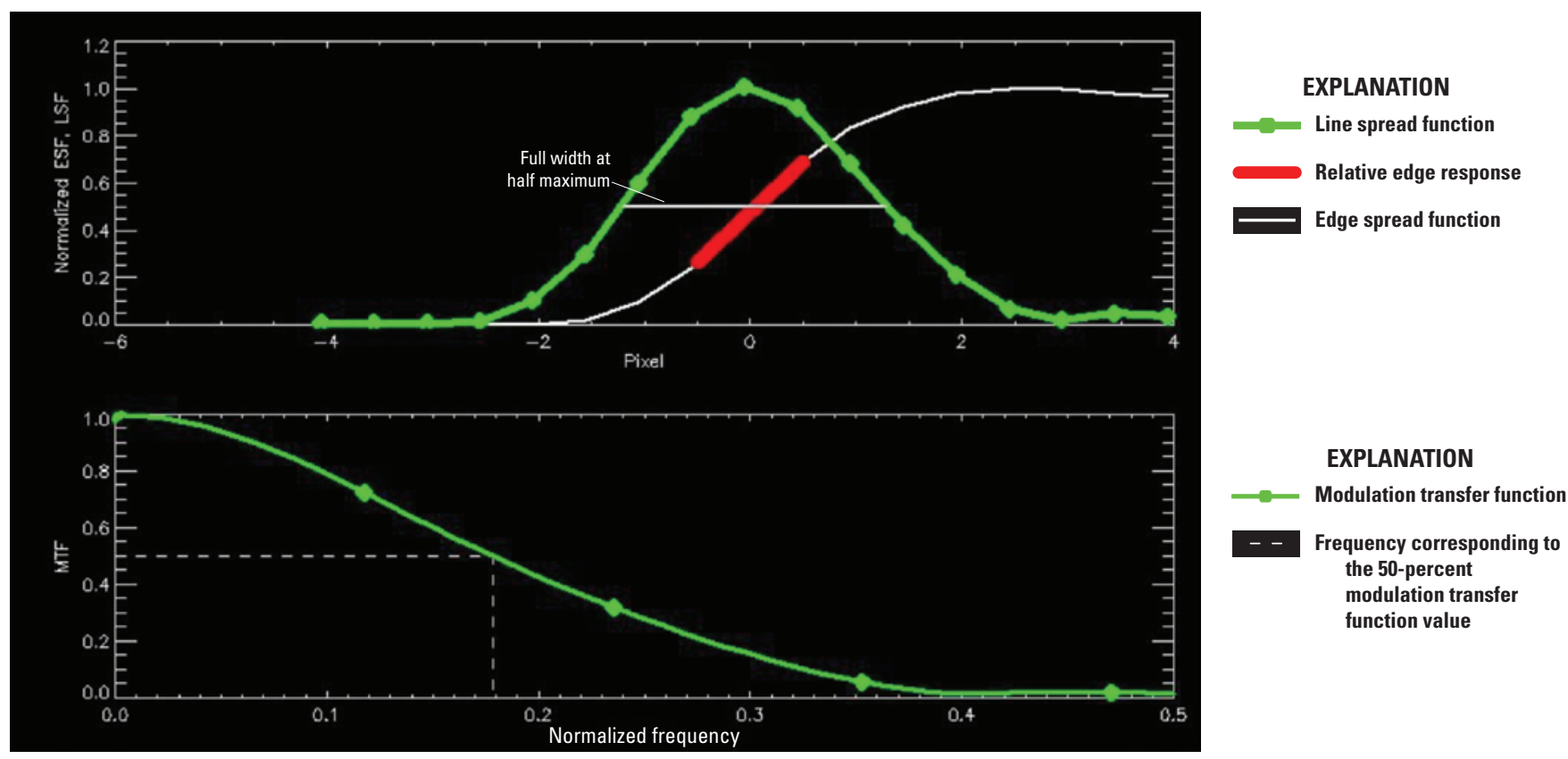

Figure 17. Band 3 (red) edge spread function (ESF) and line spread function (LSF; upper) and modulation transfer function (MTF; lower). 


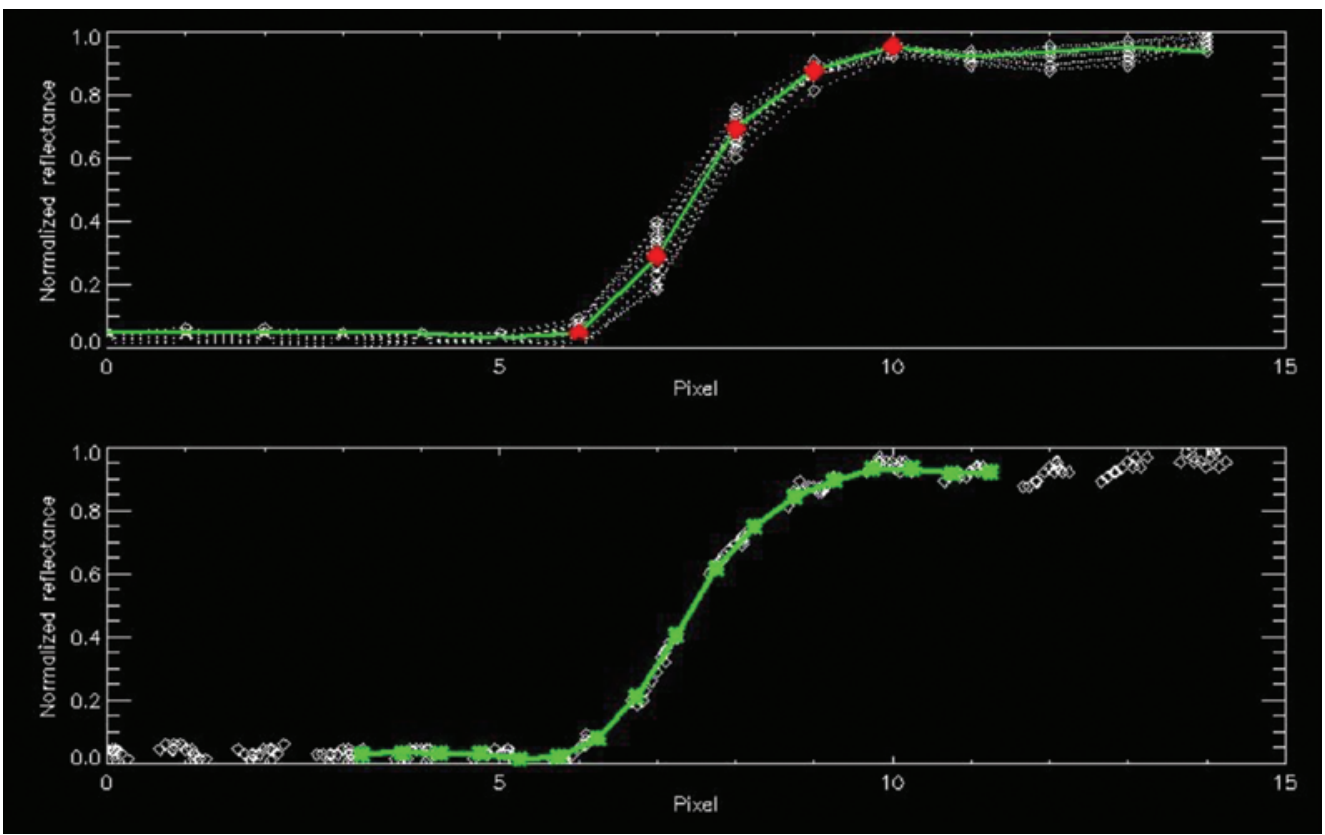

\section{EXPLANATION}

Middle transect

S. Raw transect

Region of the curve used for alignment

\section{EXPLANATION}

- Edge spread function

$\Delta \quad$ Aligned transect

Figure 18. Band 4 (near infrared) raw edge transects (upper) and aligned transects (lower).

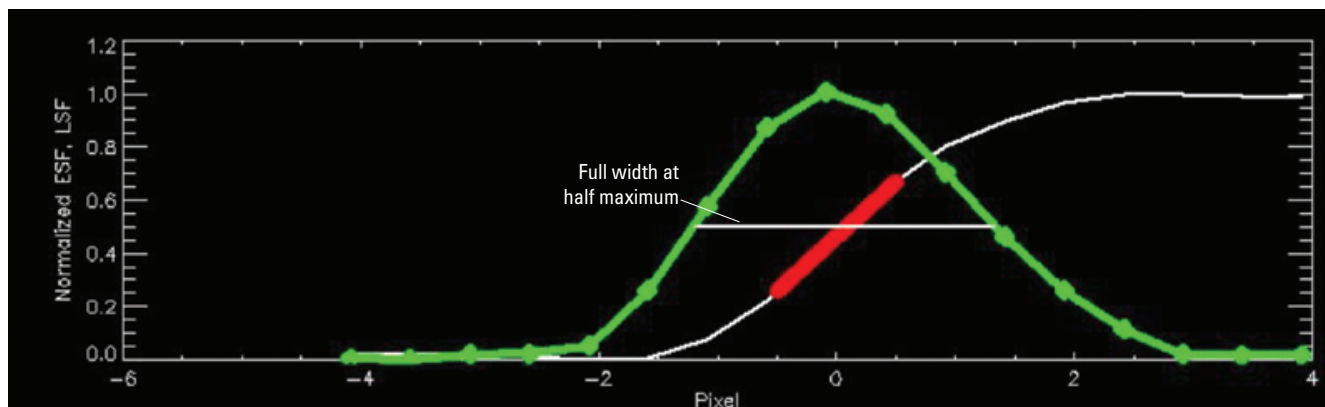

\section{EXPLANATION}

- Line spread function

Relative edge response

Edge spread function

\section{EXPLANATION}

Modulation transfer function

Frequency corresponding to the 50-percent

modulation transfer function value

Figure 19. Band 4 (near infrared) edge spread function (ESF) and line spread function (LSF; upper) and modulation transfer function (MTF; lower). 


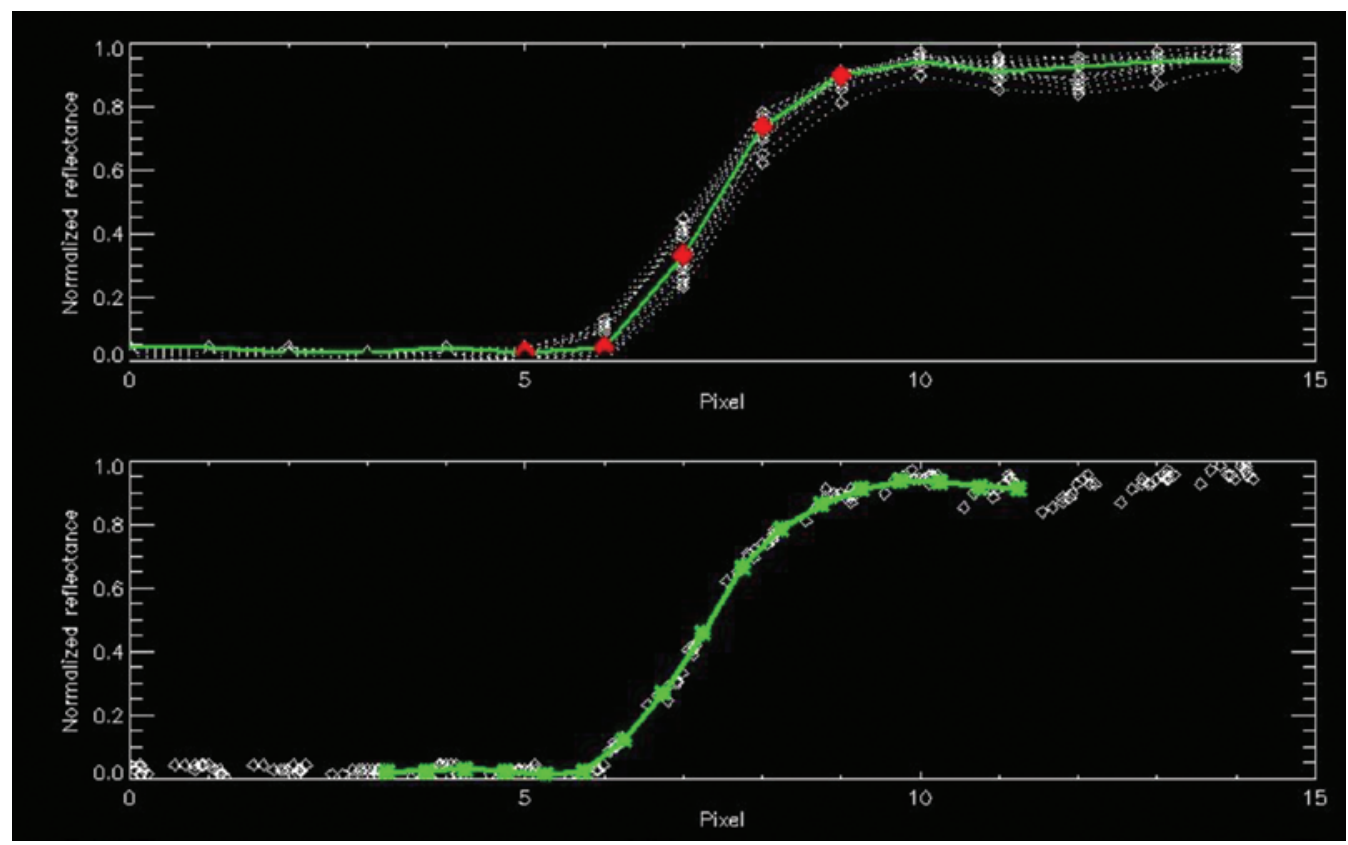

\section{EXPLANATION}

Middle transect

Raw transect

Region of the curve used

for alignment

\section{EXPLANATION}

-i:- Edge spread function

$\Delta$ Aligned transect

Figure 20. Band 5 (shortwave infrared) raw edge transects (upper) and aligned transects (lower).
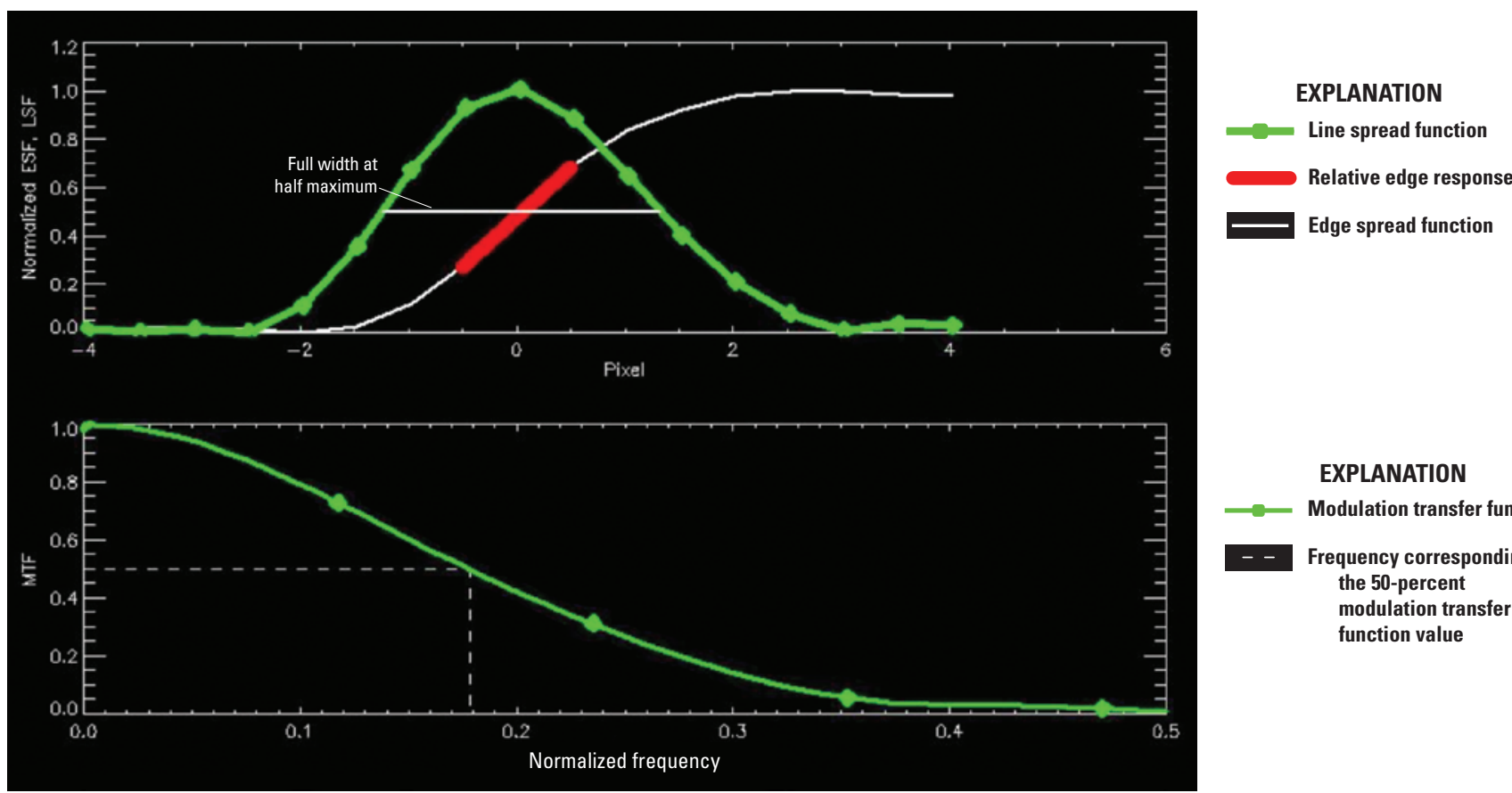

- Modulation transfer function

Frequency corresponding to the 50-percent

modulation transfer function value

\section{EXPLANATION}

Figure 21. Band 5 (shortwave infrared) edge spread function (ESF) and line spread function (LSF; upper) and modulation transfer function (MTF; lower). 


\section{Summary and Conclusions}

This report summarizes the sensor performance of the Resourcesat-2 Linear Imaging Self Scanning-3 (LISS-3) sensor based on the U.S. Geological Survey Earth Resources Observation and Science Cal/Val Center of Excellence (ECCOE) system characterization process. In summary, we have determined that this sensor provides an interior geometric performance in the range of $-4.620(-0.154$ pixel $)$ to $13.230 \mathrm{~m}(0.441$ pixel $)$ in easting and $-12.360(-0.412$ pixel $)$ to $1.500 \mathrm{~m}(0.050$ pixel $)$ in northing in band-to-band registration, an exterior geometric error of $-27.805(-0.927$ pixel) to $26.578 \mathrm{~m}(0.886 \mathrm{pixel})$ in easting and $-35.341(-1.178$ pixel $)$ to $-6.286 \mathrm{~m}$ ( -0.210 pixel) in northing offset in comparison to the Landsat 8 Operational Land Imager, a radiometric performance in the range of -0.108 to 0.104 in offset and $0.585-0.946$ in slope, and a spatial performance in the range of 2.52-2.57 pixels for full width at half maximum, with a modulation transfer function at a Nyquist frequency in the range of $0.018-0.028$.

In conclusion, the team has completed an ECCOE standardized system characterization of the Resourcesat- 2 LISS-3 sensing system. Although the team followed characterization procedures that are standardized across the many sensors and sensing systems under evaluation, these procedures are customized to fit the individual sensor as was done with LISS-3. The team has acquired the data, defined proper testing methodologies, carried out comparative tests against specific references, recorded measurements, completed data analyses, and quantified sensor performance accordingly. The team also endeavored to retain all data, measurements, and methods. This is key to ensure that all data and measurements are archived and accessible and that the performance results are reproducible.

The ECCOE project and associated Joint Agency Commercial Imagery Evaluation partners are always interested in reviewing sensor and remote sensing application assessments and would like to see and discuss information on similar data and product assessments and reviews. If you would like to discuss system characterization with the U.S. Geological Survey ECCOE and (or) the Joint Agency Commercial Imagery Evaluation team, please email us at eccoe@usgs.gov.

\section{Selected References}

Indian Space Research Organisation, 2021, Resourcesat-2: Indian Space Research Organisation web page, accessed June 2021 at https://www.isro.gov.in/Spacecraft/ resourcesat-2.

Ramaseri Chandra, S.N., Christopherson, J.B., and Casey, K.A., 2020, 2020 Joint Agency Commercial Imagery Evaluation-Remote sensing satellite compendium: U.S. Geological Survey Circular 1468 (ver. 1.1, October 2020), 253 p. [Also available at https://doi.org/10.3133/cir1468.] [Supersedes USGS Circular 1455.]

U.S. Geological Survey, 2020a, EROS CalVal Center of Excellence (ECCOE): U.S. Geological Survey web page, accessed June 2021 https://www.usgs.gov/core-sciencesystems/eros/calval.

U.S. Geological Survey, 2020b, EROS CalVal Center of Excellence (ECCOE) - JACIE: U.S. Geological Survey web page, accessed June 2021 at https://www.usgs.gov/ core-science-systems/eros/calval/jacie?qt-science_support page_related_con $=3 \#$ qt-science_support_page_related_con.

U.S. Geological Survey, 2020c, Landsat missions-Glossary and acronyms: U.S. Geological Survey web page, accessed June 2021 at https://www.usgs.gov/core-science-systems/ nli/landsat/glossary-and-acronyms. 

For more information about this publication, contact: Director, USGS Earth Resources Observation and Science Center 47914 252nd Street

Sioux Falls, SD 57198

605-594-6151

For additional information, visit: https://www.usgs.gov/centers/eros

Publishing support provided by the

Rolla Publishing Service Center 


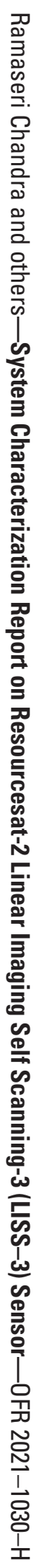

